\title{
Enteric glial cells favour accumulation of anti-inflammatory macrophages during the resolution of muscularis inflammation
}

\author{
Short title: EGC-M $\varphi$ interaction in muscularis inflammation
}

\begin{abstract}
Michelle Stakenborg1, \#, Saeed Abdurahiman", \#, Veronica De Simone1, Gera Goverse ${ }^{1}$, Nathalie Stakenborg ${ }^{1}$, Lies van Baarle ${ }^{1}$, Qin Wu' ${ }^{1}$, Dimitri Pirottin², Jung-Seok Kim³, Louise Chappell-Maor ${ }^{3}$, Isabel Pintelon ${ }^{4}$, Sofie Thys ${ }^{4}$, Louis Boon ${ }^{5}$, Marlene Hao ${ }^{1}$, Jo A. Van Ginderachter $^{6,7}$, Guy E. Boeckxstaens ${ }^{1}$, Jean-Pierre Timmermans ${ }^{4}$, Steffen Jung ${ }^{3}$, Thomas Marichal $^{8,9}$, Sales Ibiza ${ }^{1,4, *}$, Gianluca Matteoli ${ }^{1, *}$
\end{abstract}

\section{Affiliation}

${ }^{1}$ Department of Chronic Diseases, Metabolism and Ageing (CHROMETA), Translational Research Center for Gastrointestinal Disorders (TARGID), KU Leuven, Leuven, Belgium.

${ }^{2}$ Laboratory of Cellular and Molecular Immunology, GIGA Institute, Liege University, Liege, Belgium.

${ }^{3}$ Department of Immunology, Weizmann Institute of Science, Rehovot, Israel.

${ }^{4}$ Laboratory of Cell Biology \& Histology, Department of Veterinary Sciences, University of Antwerp, Antwerp, Belgium.

${ }^{5}$ Polpharma Biologics, Utrecht, the Netherlands.

${ }^{6}$ Cellular and Molecular Immunology Lab, Department of Bio-engineering Sciences, Vrije Universiteit Brussel, Brussels, Belgium.

${ }^{7}$ Myeloid Cell Immunology Lab, VIB Center for Inflammation Research, Brussels, Belgium.

${ }^{8}$ Laboratory of Immunophysiology, GIGA Institute, Liege University, Liege, Belgium.

${ }^{9}$ Department of Functional Sciences, Faculty of Veterinary Medicine, Liege University, Liege, Belgium.

\#, these authors contributed equally to this work.

*, senior authors: Sales Ibiza and Gianluca Matteoli

\section{Corresponding author:}

Prof. Sales Ibiza, PhD

Laboratory of Cell Biology \& Histology

Department of Veterinary Sciences University of Antwerp,

Campus Drie Eiken, Universiteitsplein 1, B-2610 Wilrijk, Belgium

$\mathrm{T}+32-3-2653324$

Email: Sales.IbizaMartinez@uantwerpen.be

Prof. Gianluca Matteoli, DVM, PhD

Laboratory of Mucosal Immunology

Department of Chronic Diseases, Metabolism and Ageing (CHROMETA)

KU Leuven, Herestraat 49, O\&N1 box 701| BE-3000 Leuven | Belgium

Tel. + 32 (0)16 377566

Email: gianluca.matteoli@kuleuven.be 


\section{Abstract}

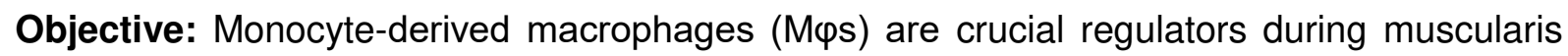
inflammation. However, it is unclear which microenvironmental factors are responsible for monocyte recruitment and neurotrophic $M \varphi$ differentiation in this paradigm. Here, we investigate $M \varphi$ heterogeneity at different stages of muscularis inflammation and determine how environmental cues can attract and activate tissue protective M $\varphi s$.

Design: Single cell RNA sequencing was performed on immune cells from the muscularis of wild-type and CCR2 ${ }^{-/-}$mice at different timepoints after muscularis inflammation. CX3CR1 GFP/+ and CX3CR $1^{\text {CreERT2 }}$ R26 ${ }^{\text {YFP }}$ mice were analyzed by flow cytometry and immunofluorescence. The transcriptome of enteric glial cells (EGCs) was investigated using PLPCreERT2 Rpl$^{2} 2^{\mathrm{HA}}$ mice. In addition, we assessed the effect of supernatant from neurosphere-derived EGCs on monocyte differentiation based on the expression of pro- and anti-inflammatory factors.

Results: Muscularis inflammation induced marked alterations in mononuclear phagocyte populations associated with a rapid infiltration of $\mathrm{Ly}_{6 \mathrm{C}} \mathrm{c}^{+}$monocytes that locally acquired unique transcriptional states. Trajectory inference analysis revealed two main pro-resolving $\mathrm{M} \varphi$ subpopulations during the resolution of muscularis inflammation, i.e. $\mathrm{Cd}_{206} \mathrm{Mhcll}^{\mathrm{hi}}$ and $\mathrm{Timp}^{+} \mathrm{Mhcll}^{\mathrm{lo}} \mathrm{M} \varphi \mathrm{s}$, which were both derived from CCR2 ${ }^{+}$monocytes. Interestingly, we found that EGCs were able to sense damage to the muscularis to stimulate monocyte recruitment and differentiation towards pro-resolving M $\varphi s$ via CCL2 and CSF1, respectively.

Conclusion: Our study provides a comprehensive insight into pro-resolving $M \varphi$ differentiation and their regulators during muscularis inflammation. We deepened our understanding in the interaction between $\mathrm{EGCs}$ and $\mathrm{M} \varphi \mathrm{s}$, thereby highlighting pro-resolving $\mathrm{M} \varphi$ differentiation as a potential novel therapeutic strategy for the treatment of intestinal inflammation.

Key Words: Muscularis externa, resolution of inflammation, macrophages, enteric glial cells. 
bioRxiv preprint doi: https:/doi.org/10.1101/2021.06.10.447700; this version posted June 10, 2021. The copyright holder for this preprint

(which was not certified by peer review) is the author/funder, who has granted bioRxiv a license to display the preprint in perpetuity. It is made available under aCC-BY-NC-ND 4.0 International license.

\section{Introduction}

In recent years, significant advances have been made in our understanding of the phenotype of intestinal macrophages (M $(\mathrm{s})$, which perform niche-defined functions to maintain immune homeostasis and regulate motility and secretion via the enteric nervous system (ENS) ${ }^{1-3}$. Consequently, specific niches are populated by different $M \varphi$ subsets with a unique transcriptome to meet the diverse functional demands of the tissue microenvironment. For instance, lamina propria M $\varphi s$ reside in close proximity to the epithelium and at the crypt base, where they are involved in the maintenance of gut homeostasis by contributing to epithelial barrier integrity and by phagocytosing luminal antigens ${ }^{2-5}$. In the deeper layers of the gut wall at the level of the muscularis externa, M $\varphi s$ exert neurotrophic functions to promote enteric neuron survival and to support neuronal function ${ }^{1,6,7}$. However, during muscularis inflammation, activation of resident M $\varphi s$ results in impairment of neuromuscular function due to the release of nitric oxide, prostaglandins and cytokines, simultaneously triggering the influx of inflammatory cells ${ }^{8-10}$. Although we have shown in a previous study that the influx of monocytes is essential for the resolution of muscularis inflammation due to their differentiation into pro-resolving monocyte-derived $M \varphi s^{11}$, it remains to be determined which cell types are responsible for monocyte recruitment and which factors promote their differentiation towards anti-inflammatory $M \varphi s$ during muscularis inflammation. The extensive crosstalk between muscularis M $M S$ and the ENS at homeostasis suggests a potential involvement during inflammation ${ }^{6}$. The ENS is organized in a network of ganglia containing neurons and enteric glial cells (EGCs). Historically, EGCs were mainly considered as supporting cells of enteric neurons. However, recent evidence suggests that EGCs have a much broader function in gastro-intestinal (GI) physiology, contributing to motility and preserving epithelial barrier integrity by the interaction with innate lymphoid cells (ILCs), interstitial cells of Cajal, endothelial and epithelial cells ${ }^{12-17}$. Even more intriguing is the putative role of EGCs in immune regulation. In this regard, the interaction between astrocytes and microglia has been 
extensively studied in the brain during development, homeostasis and disease ${ }^{18}$. Yet, limited studies have investigated the interaction between M $\varphi s$ and EGCs in the intestine ${ }^{19}$.

Here, we investigate $M \varphi$ heterogeneity and their role in tissue repair during muscularis inflammation. Using time-series single-cell transcriptomics, we observed that muscularis inflammation induced a prominent myeloid cell diversification, resulting in 7 myeloid subpopulations. Trajectory inference analysis indicated that incoming Ly6 $6 c^{\text {hi }}$ monocytes acquired diverse gene expression signatures in the injured muscularis, notably resulting in two main pro-resolving $\mathrm{M} \varphi$ subpopulations characterized by $\mathrm{Cd} 206^{+} \mathrm{Mhcll}^{\mathrm{hi}}$ and $\mathrm{Timp}^{+} \mathrm{Mhcll}^{\mathrm{lo}}$ gene signatures. In addition, EGCs were identified as the main producers of the monocyte chemo-attractant, CCL2, during the early phase of inflammation. Furthermore, these cells produced a multitude of secreted factors that can potentially stimulate the differentiation of monocytes into pro-resolving M $\varphi$ s. Specifically, we defined EGC-derived CSF1 as a critical

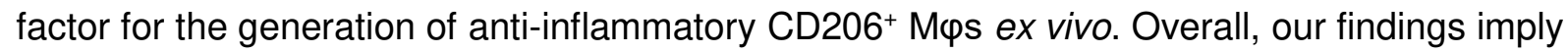
that during intestinal inflammation, future therapies should be aimed at enhancing the proresolving and neurotrophic properties of M $\varphi$ s to reduce possible damage to the ENS and promote GI recovery. 


\section{Material \& methods}

Mouse Model. Twelve week old female wild-type (WT; C57BL/6J), CCR2 knockout (CCR2---

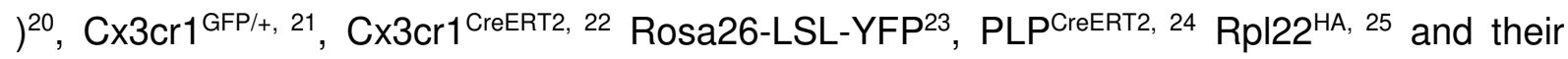
littermate controls were used. All lines were bred and maintained at the KU Leuven animal facility on a 12:12-h light-dark cycle and had ad libitum access to tap water and commercially available chow (ssniff® R/M-H, ssniff Spezialdiäten $\mathrm{GmbH}$ ). All experimental procedures were approved by the Animal Care and Animal Experiments Ethical Committee of KU Leuven.

Experimental model of small intestinal inflammation. An established model of intestinal manipulation was used to induce small intestinal muscularis inflammation as previously reported $^{26}$. In brief, animals were anesthetized by intraperitoneal injection of ketamine (Ketalar $100 \mathrm{mg} / \mathrm{kg}$; Pfizer) and xylazine (Rompun $10 \mathrm{mg} / \mathrm{kg}$; Bayer). After a midline laparotomy, the cecum and the small intestine were carefully externalized and mounted onto a plexiglas platform. Next, the small intestine was manipulated three times back and forth using a purposedesigned device that enables the application of a constant pressure to the intestine by a cotton swab applicator attached to its end.

Statistical analysis. Results are shown as mean \pm standard error of the mean (SEM). Significance between two mean groups was determined by an unpaired two-tailed Student's ttest or a non-parametric Mann-Whitney test, while one-way analysis of variance (one-way ANOVA) followed by Dunnett's Multiple comparison test was performed to compare the mean of multiple groups. GraphPad Prism V.9.1.0 software (GraphPad Inc) was used to generate graphs and to perform statistical analysis. 


\section{$\underline{\text { Results }}$}

\section{Time-dependent recruitment of immune cell in the inflamed muscularis}

Surgery-induced damage to the muscularis leads to a transient impairment of GI motility associated with extensive recruitment of immune cells to the ENS. To characterize the immune cell infiltrate and their respective activation states during muscularis inflammation, dropletbased scRNA-seq was performed on sorted CD45+ immune cells from the muscularis of naïve mice, and during the acute (24h) and resolving phase of muscularis inflammation (72h) (10X Genomics Platform; Fig. 1A). Unsupervised clustering of 4,102 cells and reference-based identification using Immgen (Fig. 1B-C and Supplementary Fig. 1A-B) revealed 12 independent immune cell populations including monocytes (Ccr2, Ly6c2, Chil3), 3 clusters of Mys (1: Cd63, Cd68, Trem2; 2: Itgam, Arg1, Lyz2; 3: Cx3cr1, Csf1r, Mrc1), dendritic cells (DCs; Itgax, Cd209a, Ccl17), 2 clusters of neutrophils (1: Cxcr2, Mmp9, S100a9; 2:, S100a8, Hcar2, Msrb1), eosinophils (Siglec-f, Cxcr4, Pim1), ILCs (Thy1, Rora, II7r), T cells (Cd3e, Cd7, Trdc) and 2 clusters of B cells (1: Cd79a, Cd20, CD79b; 2: Eaf2, Mef2b, CD19) ${ }^{27}$.

To examine the role of different immune cell populations, we determined their gene expression signatures at different time points during muscularis inflammation. At homeostasis, the muscularis mainly consisted of a population of $\mathrm{C} \times 3 \mathrm{cr} 1^{+} \mathrm{M} \varphi s\left(\mathrm{M} \varphi \_3\right)$ together with T cells, $\mathrm{B}$ cells and ILCs (Fig. 1D-E). In the acute and resolving phase of muscularis inflammation, and consistent with previous observations ${ }^{11,28}$, a shift in the leukocyte populations with respect to the homeostatic condition was observed (Fig. 1D-E). In the acute phase (24h), there was a massive infiltration of monocytes in addition to $M \varphi s\left(M \varphi \_1\right.$ and $\left.M \varphi \_2\right)$ and neutrophils (Neu_1 and Neu_2), pointing towards a more pro-inflammatory micro-environment. During the resolution of muscularis inflammation (72h), the muscularis was mainly populated by $\mathrm{Cx} 3 \mathrm{cr} 1^{+}$ $\mathrm{M} \varphi \mathrm{s}\left(\mathrm{M} \varphi \_3\right)$, DCs and eosinophils, indicating a return to homeostasis. Altogether, these results show that during muscularis inflammation a shift in the immune landscape favors the resolution of inflammation and a rapid return to homeostasis. 


\section{Identification of two distinct myeloid subpopulations during the resolution of}

\section{muscularis inflammation}

Monocyte-derived M $\varphi$ s are essential for the recovery of Gl motility during the resolution of muscularis inflammation ${ }^{11,28}$. However, their heterogeneity and differentiation trajectory towards tissue protective M $\varphi s$ have not yet been characterized during muscularis inflammation. To this end, subsets originally identified as monocyte/M $\varphi$ subpopulations in our scRNAseq dataset (Fig. 1) were extracted and re-clustered to better define which type of myeloid cells might aid in the resolution of muscularis inflammation, thereby identifying 7 distinct subsets (Fig. 2A-D and Supplementary Fig. 2A). At homeostasis, the muscularis micro-environment mainly consisted of $\mathrm{C} \times 3 \mathrm{cr} 1^{+} \mathrm{M} \varphi s$ with high expression of typical resident $\mathrm{M} \varphi$ markers such as $C d 81, C d 72$ and $H 2-E b 1$ (Fig. 2E). During acute muscularis inflammation, the most predominant subpopulation was the cluster of classical Ly6 $\mathrm{c}^{+}$monocytes, which was enriched for the expression of Plac8, Hp and Chil3 (Fig. 2B-E). Additionally, a subpopulation with a gene expression signature suggestive of an intermediate monocyte-to-M $\varphi$ differentiation state was observed $\left(\mathrm{Ccr}^{+}\right.$int $\left.\mathrm{M} \varphi s\right)$, which was underscored by their moderate Mhcll expression as compared to Ly6c $\mathrm{c}^{+}$monocytes and homeostatic Cx3cr1+ $\mathrm{M} \varphi$ s (Fig. 2B). Besides Ly6c $\mathrm{c}^{+}$monocytes and $\mathrm{Ccr}^{+}$int M $\mathrm{Ss}$, we observed a subcluster of $\mathrm{Arg} 1^{+} \mathrm{Mo} / \mathrm{M} \varphi$ with high expression of $\mathrm{Cc} / 9$ and Srgn alongside Fabp5 ${ }^{+} \mathrm{Mo} / \mathrm{M} \varphi$ with characteristic expression of Lgals 1 , Ccl7 and Flt1 (Fig. 2E). Of note, 72h post-injury, during the resolution of muscularis inflammation, Ly $6 \mathrm{c}^{+}$monocytes and $\mathrm{Ccr}^{+}$int $\mathrm{M} \varphi s$ were present at a low percentage but two novel M $\varphi$ subclusters were identified: $\mathrm{Cd}_{206}{ }^{+} \mathrm{M} \varphi s$ and $\mathrm{Timp}^{+} \mathrm{M} \varphi s$ (Fig. 2C-D and Supplementary Fig. 2B). The most abundant subcluster during the resolution of muscularis inflammation, Cd206+ M $\varphi s$, displayed high Mhcll expression similar to homeostatic Cx3cr1 ${ }^{+}$ $\mathrm{M} \varphi \mathrm{s}$, in addition to high expression of anti-inflammatory genes such as Selenop, Mrc1, Igf1, Trem2 and Stab1 (Fig. 2B and Supplementary Fig. 2B-C). In contrast, Timp2 ${ }^{+}$M $\varphi s$ had lower Mhcll expression compared to homeostatic $\mathrm{C} \times 3 \mathrm{cr} 1^{+} \mathrm{M} \varphi \mathrm{s}$, but similarly expressed high levels of tissue reparative markers such as Ltc4s and Adgre5 (Fig. 2B, 2E and Supplementary Fig. 
bioRxiv preprint doi: https:/doi.org/10.1101/2021.06.10.447700; this version posted June 10, 2021. The copyright holder for this preprint (which was not certified by peer review) is the author/funder, who has granted bioRxiv a license to display the preprint in perpetuity. It is made available under aCC-BY-NC-ND 4.0 International license.

2B-C). To further investigate differences in the transcriptional regulation of $\mathrm{Cd} 206^{+}$and $\mathrm{Timp}^{+}$ $\mathrm{M} \varphi s$, single-cell regulatory network inference and clustering (SCENIC) was employed to assess specific regulon activities in different myeloid subclusters (Fig. 2F and Supplementary Fig. 2F). Cd206+ Mps displayed high regulon activity of FosB, Runx1 and Irf8 similar to Cx3cr1+ M $\varphi s$, while Timp2 $2^{+}$M $\varphi$ s had a distinctly altered transcription factor signature with high Cebpb and Gata6 regulon activity.

To evaluate whether these subclusters can also be detected by flow cytometry, a comparative study was performed during muscularis inflammation. In the healthy muscularis, only 1 subset

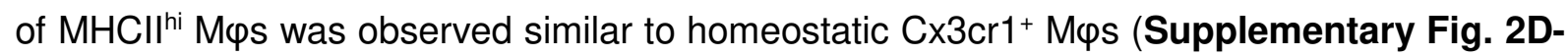
E). During acute muscularis inflammation, the muscularis microenvironment was mainly dominated by infiltrating Ly6 $\mathrm{C}^{\text {hi }}$ monocytes, which differentiated into $\mathrm{Ly}_{6} \mathrm{C}^{+} \mathrm{MHCI}^{+}$immature M $\varphi$ s. However, at single cell level, we observed 4 different $M \varphi$ subclusters, indicating that $M \varphi$ heterogeneity was higher than originally considered. Interestingly, $72 \mathrm{~h}$ post-injury, flow cytometric analysis also revealed only two main $\mathrm{M} \varphi$ subclusters $\left(\mathrm{MHCI}^{\mathrm{hi}}\right.$ and $\left.\mathrm{MHCII}{ }^{\mathrm{lo}} \mathrm{M} \varphi \mathrm{s}\right)$, similar to our observations at single cell level (Supplementary Fig. 2D-E).

Identifying relevant gene expression changes in myeloid subclusters during muscularis inflammation could shed light on the molecular mechanism regulating $M \varphi$ differentiation. In order to define these temporal transcriptional alterations leading to differentiation into $\mathrm{Cd} 206^{+}$ and Timp2 ${ }^{+}$M $\varphi s$, Monocle-2 was used to superimpose subclusters on a trajectory placing Ly6c $\mathrm{c}^{+}$monocytes at the beginning of the pseudotime (Fig. $\left.2 \mathrm{G}-\mathbf{H}\right)^{29}$. We identified a major trajectory bifurcation leading to a branch of cells with high expression of genes found in homeostatic M $\varphi$ s such as Cd74, Tmem176a/b, complement genes (C1qa, C1qb, C1qc) and Mhcll genes (H2-Eb1, H2-Ab1, H2-Aa; Branch 1), while the other branch had less complement and Mhcll expression with increased expression of Fn1, Ltc4s and Saa3 (Branch 2) (Fig. 2H and Supplementary Fig. 2G-H). Interestingly, the $\mathrm{Cd}_{206^{+}}$and $\mathrm{Timp}^{+} \mathrm{M} \varphi$ subsets were at two opposite ends of the trajectory suggesting alternative differentiation routes during the resolution of muscularis inflammation (Fig. 2G). Of note, homeostatic Cx3cr1 ${ }^{+} \mathrm{M} \varphi s$ were 
located in close proximity to $\mathrm{Cd} 206^{+} \mathrm{M} \varphi \mathrm{s}$ in the pseudotime, underscoring the similarity between both $\mathrm{M} \varphi$ subsets. Arg1+ and Fabp5 $5^{+} \mathrm{Mo} / \mathrm{M} \varphi$ were mainly present in Branch 2, while $\mathrm{Ccr}^{+}$int M $\varphi$ s were exclusively present in Branch 1, indicating that these subpopulations might act as intermediates before attaining their terminal differentiation state. These findings support the hypothesis that there are two major monocyte-to-M $\varphi$ differentiation trajectories in the inflamed muscularis giving rise to $\mathrm{Cd}_{206^{+}}$and $\mathrm{Timp}^{+} \mathrm{M} \varphi s$ during the resolution of inflammation.

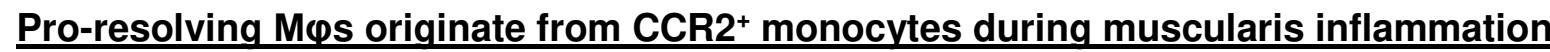

In a previous study, we have shown that the influx of $\mathrm{CCR}^{+}$monocytes is essential for resolution of muscularis inflammation, as blocking monocyte infiltration resulted in a delayed recovery of $\mathrm{Gl}$ motility and damage to the $\mathrm{ENS}^{11}$.To investigate whether $\mathrm{CCR} 2^{+}$monocytes are the source of pro-resolving $M \varphi s$ during muscularis inflammation, scRNAseq was performed on sorted CD45+ immune cells from the muscularis of WT and CCR2 ${ }^{-/-}$mice $24 \mathrm{~h}$ and $72 \mathrm{~h}$ post-injury (Fig. 3A-C and Supplementary Fig. 3A-D). After extraction and reclustering of the mono/M $\mathrm{\varphi}$ subsets $(2,406$ cells), the gene expression signatures from the myeloid subsets in Fig. 2 were crossmatched by singleR with this novel dataset to specifically annotate the subpopulations (Supplementary Fig. 3C), yielding only one additional cluster, i.e. $F n 1^{+}$mono/M $\varphi s$. In $\mathrm{CCR} 2^{-/-}$mice, there was a large alteration in the myeloid compartment after muscularis inflammation. As expected upon acute muscularis inflammation in $\mathrm{CCR}^{-1-}$ mice, there was an almost complete loss of $\mathrm{Ly}_{6 \mathrm{c}} \mathrm{c}^{+}$monocytes, and Arg1+ and Fabp5 ${ }^{+} \mathrm{Mo} / \mathrm{M} \varphi \mathrm{s}$. In addition, we could only detect a small subpopulation of $\mathrm{C} \times 3 \mathrm{cr} 1^{+} \mathrm{M} \varphi$ s representing the long-

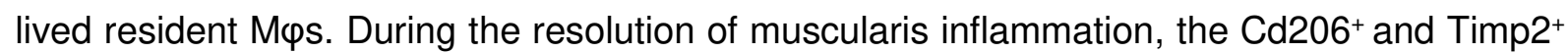
$\mathrm{M} \varphi$ subsets were also completely absent in $\mathrm{CCR} 2^{-/-}$mice, confirming that these subpopulations are derived from $\mathrm{CCR}_{2}{ }^{+}$monocytes and that they possibly represent the pro-resolving $\mathrm{M} \varphi s$ essential for recovery of GI motility after tissue damage. 
To further investigate the phenotype of $\mathrm{Cd}_{206}{ }^{+}$and $\mathrm{Timp}^{+} \mathrm{M} \varphi s$ during muscularis inflammation, gene ontology (GO) analysis was performed and revealed that both $\mathrm{M} \varphi$ subsets seemed pro-resolving in nature (Fig. 3D). For instance, Timp2 ${ }^{+} M \varphi s$ were implicated in pathways associated with tissue repair and regulation of the inflammatory response, such as angiogenesis, response to wounding, blood vessel development, icosanoid biosynthetic processes, and phagocytosis-engulfment. Conversely, Cd206 ${ }^{+} \mathrm{M} \varphi s$ were enriched for pathways associated with antigen processing and presentation via MHC class II, negative regulation of oligodendrocyte and glial cell apoptotic processes and positive regulation of gliogenesis. In contrast, monocytes were clearly enriched for pro-inflammatory pathways, such as type I interferon signaling and positive regulation of immune system processes.

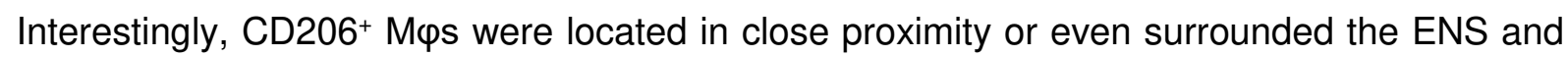
outnumbered TIMP2+ M ${ }^{+}$s, which were located further away from the ENS (Fig. 3E). To confirm that $\mathrm{Cd} 206^{+} \mathrm{Mhcll}^{\text {hi }} \mathrm{M} \varphi$ s have a neuroprotective on the ENS, we next aimed to assess their contribution on EGC proliferation in vitro (Fig. 3F). While Ly6c monocytes isolated $24 \mathrm{~h}$ post-injury did not alter the proliferation of EGCs, MHCII $\mathrm{M}$ h $\mathrm{s}$ from $72 \mathrm{~h}$ post-injury induced EGC proliferation, underscoring their role in supporting EGC function (Fig. 3G). These results establish that $\mathrm{CCR}^{+}$monocytes differentiate into two distinct $\mathrm{M} \varphi$ subpopulations with proresolving and/or neurotrophic functions.

\section{CX3CR1-based mapping shows unique M $\varphi$ subsets similar to scRNAseq}

To further define the phenotype of the $M \varphi$ subpopulations identified using scRNA at the protein level, we induced muscularis inflammation in CX3CR1 ${ }^{\text {gfp/+ }}$ mice (Fig. 4A-B). Upon muscularis inflammation, the percentage of homeostatic $\mathrm{CX} 3 \mathrm{CR} 1^{\text {hi }} \mathrm{M} \varphi \mathrm{s}$ was drastically reduced with a concomitant increase of $\mathrm{CX} 3 \mathrm{CR} 1^{10} \mathrm{MHCII}^{\text {hi }}$ and CX3CR1 $1^{10} \mathrm{MHCI}{ }^{\mathrm{lo}} \mathrm{M} \varphi s$. As CCR2 and CD206 have been described as essential markers for recruited and anti-inflammatory $\mathrm{M} \varphi s$ respectively, their protein levels were determined in these CX $3 C R 1^{\text {hilo }} M \varphi$ subpopulations (Fig. 4C-H and Supplementary Fig. 4A-B). In line with previous findings, CX $3 \mathrm{CR} 1^{\text {hi }}$ MHCII ${ }^{\text {hi }}$ M $\varphi s$ were mainly CD206+ and CCR2 ${ }^{-}$at homeostasis (Fig. 4C-E). However, this subpopulation 
was gradually replaced by a combination of $\mathrm{CX} 3 \mathrm{CR} 1^{10} \mathrm{MHCI}{ }^{10}$ and $\mathrm{CX} 3 \mathrm{CR} 1^{10} \mathrm{MHCI}{ }^{\mathrm{hi}} \mathrm{M} \varphi s$, resembling Timp2 ${ }^{+}$and Cd206 ${ }^{+} \mathrm{M} \varphi$ s respectively (Fig. 4C-H). Interestingly, CD206+ CX3CR1 $1^{10}$

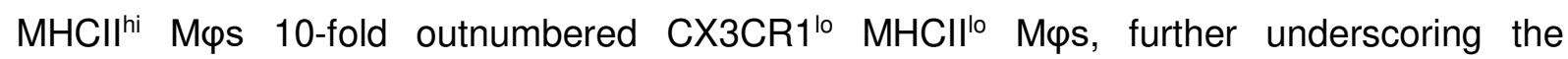
importance of these anti-inflammatory $\mathrm{Cd} 206^{+} \mathrm{Mhcll}^{\text {hi }} \mathrm{M} \varphi \mathrm{S}$ (Supplementary Fig. 4A-B). Overall, our data validated at protein level the presence of two distinct $M \varphi$ subpopulations during the resolution of muscularis inflammation which are derived from $\mathrm{CCR} 2^{+}$monocytes and are anti-inflammatory in nature.

Similar to our scRNAseq dataset, we observed a drastic reduction in the percentage of homeostatic CX3CR1 ${ }^{\text {hi }}$ M $\varphi s$ upon the induction of muscularis inflammation (Fig. 2C-D). To determine whether these $\mathrm{CX} 3 \mathrm{CR} 1^{\text {hi }} \mathrm{M} \varphi \mathrm{s}$ are replaced by incoming monocyte-derived $\mathrm{M} \varphi \mathrm{S}$, $\mathrm{CX} 3 \mathrm{CR} 1^{+}$resident $\mathrm{M} \varphi$ s were mapped by using the tamoxifen-inducible $\mathrm{CX} 3 \mathrm{CR} 1^{\text {CreERT2 }}$ strain backcrossed with Rosa26-LSL-YFP mice. By comparing circulating unlabeled blood monocytes with resident $\mathrm{YFP}^{+} \mathrm{M} \varphi \mathrm{s}$, we could show that resident $\mathrm{M} \varphi s$ did not diminish in number during muscularis inflammation as quantified by immunofluorescence and flow cytometry (Supplementary Fig. 4C-F). Taken together, these results indicate that $\mathrm{CX} 3 \mathrm{CR} 1^{\mathrm{hi}}$ M $\varphi s$ were present alongside $\mathrm{CX} 3 \mathrm{CR} 1^{10}$ mature $\mathrm{M} \varphi s$ during muscularis inflammation.

\section{EGC-derived CCL2 initiates the recruitment of monocytes upon muscularis}

\section{inflammation}

Monocytes originate from progenitors in the bone marrow $(\mathrm{BM})$ and rely on local chemokine production such as MCP-1/CCL2 for their recruitment at the site of inflammation ${ }^{30}$. Considering the extensive interaction between $\mathrm{CCR}^{+}$monocytes and the ENS in the inflamed muscularis ${ }^{6}$, ${ }^{11}$, we examined the production of the major chemoattractant $\mathrm{Ccl} 2$ in the muscularis during the early stage of surgery-induced inflammation. Analysis of isolated enteric ganglia $1.5 \mathrm{~h}$ postinjury showed an increased gene expression of Ccl2 and Csf1 (Fig. 5A). Moreover, immunofluorescent images showed that CCL2 was specifically produced by GFAP+ EGCs 
(Fig. 5B), leading us to conclude that during the early stages of muscularis inflammation, EGCs likely initiate the recruitment of monocytes via CCL2 to stimulate tissue repair.

To further explore the role of EGCs during the early phase of muscularis inflammation, PLPCreERT2 Rpl22 ${ }^{\mathrm{HA}}$ mice were used, which allow immunoprecipitation (IP) of ribosome-bound mRNAs from PLP1+ EGCs to study the transcriptome of EGCs at homeostasis and during early inflammation (3h post-injury) (Fig. 5C and Supplementary Fig. 5A-B) $)^{25,31,32}$. Unlike proinflammatory reactive astrocytes during brain injury ${ }^{33}$, EGCs were activated early after muscularis inflammation and produced increased amounts of factors that are able to promote the differentiation of alternatively activated M $\varphi s$, such as Lif, Serpine-1, Gdf15, Gdnf, Cxcl10 and Csf1 (Fig. 5D). To explore which pathways are activated in EGCs, gene set enrichment analysis was performed. Positive normalized enrichment scores were identified for response to ROS and cytokines, indicating that EGCs are able to sense tissue damage in the muscularis microenvironment to initiate an appropriate immune response (Fig. 5E). Interestingly, there was also an overrepresentation of genes involved in the regulation of myeloid differentiation during early muscularis inflammation in EGCs (Fig. 5E and Supplementary Fig. 5C). These results suggest that EGCs might be involved in both the recruitment and differentiation of monocytes during the early stages of muscularis inflammation.

To determine whether EGCs are able to stimulate monocyte differentiation during muscularis inflammation, we analyzed the expression of ligand-receptor pairs based on differentially expressed genes in PLP1+ EGCs 3h post-injury and $\mathrm{Ly}^{+} \mathrm{c}^{+}$monocytes undergoing differentiation into $\mathrm{Ccr} 2^{+}$int M $\varphi$ s. Their expression data was combined with prior knowledge of signaling and gene regulatory networks using Nichenet ${ }^{34}$. To identify genes regulated by the identified ligands, putative ligand-gene interactions were scored by NicheNet according to their "regulatory potential" (Fig. 5F). We next assessed whether the expression of the receptors for the putative ligand-receptor interaction were altered when $L y 6 c^{+}$monocytes underwent differentiation into Ccr2 ${ }^{+}$int M $\varphi s$ (Supplementary Fig. 5D-E). By determining a threshold for the receptor expression, we identified the following ligand-receptor interactions between EGCs 
bioRxiv preprint doi: https:/doi.org/10.1101/2021.06.10.447700; this version posted June 10, 2021. The copyright holder for this preprint (which was not certified by peer review) is the author/funder, who has granted bioRxiv a license to display the preprint in perpetuity. It is made available under aCC-BY-NC-ND 4.0 International license.

and differentiating monocytes: Csf1-Csf1r, Tgfb1-Tgfbr2/Acvrl1/Tgfbr1, Ccl2-Ccr5/Ccr1/Ccr2, Lif-Lifr/I6st, Cyr61-Itgam/ltgb2, and Psap-Lrp1 (Fig. 5G and Supplementary Fig. 5F). Taken together, EGCs are able to recruit monocytes to the site of inflammation, where they produce factors that have the potential to promote anti-inflammatory $M \varphi$ differentiation (Fig. $\mathbf{5 H}$ ).

\section{EGC-derived CSF1 promotes the differentiation of monocytes into pro-resolving CD206+}

\section{Mes.}

To directly assess the functional interaction between EGCs and monocytes, neurospherederived EGCs were analyzed by bulk RNAseq. The results revealed high expression of cytokines involved the induction of alternative $M \varphi$ differentiation (Supplementary Fig. 6A-C), similar to those observed in vivo in EGCs, including Lif, Csf1, Tgfb1 and Ccl2 (Fig. 5D, F). To demonstrate that EGC-derived factors are able to stimulate monocyte differentiation, an ex vivo model was set-up to co-culture BM monocytes with the supernatant of EGCs (Fig. 6A $)^{35}$. Co-culture of BM monocytes with EGC supernatant resulted in an upregulation of several antiinflammatory markers such as Arg1, I/10 and Mrc1, while pro-inflammatory markers were downregulated, including I/6 and I/12 (Fig. 6B). In addition, when BM monocytes were exposed to bacterial components, a similar anti-inflammatory effect of EGC supernatant was observed compared to LPS alone (Supplementary Fig. 6D). Finally, to confirm that muscularis monocytes responded to EGC supernatant in a similar fashion as BM monocytes given their different origin, ex vivo experiments were performed on sorted $\mathrm{Ly}_{6 \mathrm{C}} \mathrm{C}^{+}$monocytes from the muscularis $24 \mathrm{~h}$ post-injury (Fig. 6C). Also in this setting, monocytes acquired an antiinflammatory phenotype upon co-culture with EGC supernatant similar to that seen in BM monocytes (Fig. 6D and Supplementary Fig. 6E). Furthermore, flow cytometric analysis of BM monocytes stimulated with EGC supernatant showed increased CD206 and reduced CCR2 expression, along with increased survival compared to control monocytes (Fig. 6E-H). Taken together, our ex vivo data suggest a direct interaction between EGCs and monocytes. 
As cellular interaction analysis by Nichenet identified Csf1-Csf1r as the top candidate for potential ligand-receptor interaction between EGCs and monocytes, we next aimed to determine whether EGC-derived CSF1 had the potential to induce anti-inflammatory CD206+ M $\varphi s$ in our ex vivo co-culture model by antibody-mediated CSF1r blockade. Anti-CSF1r treatment in combination with EGC supernatant attenuated the differentiation of monocytes into pro-resolving M $\varphi$ s with reduced CD206 and increased CCR2 expression compared to cells stimulated with EGC supernatant (Fig. 6F and Supplementary Fig. 6F-H). Furthermore, we observed increased cell death of monocytes in EGC supernatant + anti-CSF1r as compared to EGC control supernatant at $48 \mathrm{~h}$ (Fig. 6E and Supplementary Fig. 6G). Altogether, these data provide evidence for a direct interaction between monocytes and EGCderived ligands ex vivo which stimulates the differentiation into pro-resolving CD206+ M $\varphi s$, which are essential for the resolution of muscularis inflammation. 


\section{Discussion}

Previous studies have shown that monocyte-derived macrophages are essential to resolve inflammation and restore gut motility following muscularis inflammation ${ }^{11,28}$. To date, it remains to be determined which $M \varphi$ subpopulations are responsible for the recovery following muscularis inflammation and which factors induce the pro-resolving $M \varphi$ phenotype essential for tissue repair. Our work provides a comprehensive overview of the differentiation of incoming monocytes into pro-resolving $M \varphi s$ during muscularis inflammation, thereby characterizing gene expression dynamics during monocyte-to-M $\varphi$ transitions and uncovering transcriptional regulators of different $M \varphi$ subpopulations. Furthermore, we have shown that upon muscularis injury the gene expression pattern of EGCs changes dramatically leading to an increased production of the monocyte chemoattract CCL2 and elevated levels of multiple mediators that could be involved in the differentiation of monocytes towards anti-inflammatory Mys, such as CSF1, during this paradigm.

Using time-resolved scRNAseq of $\mathrm{CD} 5^{+}$immune cells from the inflamed muscularis, we identified different monocyte and $M \varphi$ subpopulations at homeostasis and during acute inflammation and the resolution of inflammation. During acute muscularis inflammation, Ly6 $\mathrm{c}^{+}$ monocytes were present along with other transient monocyte/M $\varphi$ subpopulations such as $\mathrm{Fabp}^{+}$and $\mathrm{Arg} 1^{+}$mono/M $\varphi$, showing substantial heterogeneity in monocytic cells during acute inflammation, rather than a single homogenous wave of $L y 6 \mathrm{c}^{+}$monocytes. Additionally, we identified $\mathrm{Ccr}^{+}$int M $\varphi s$ as a transitional state between monocytes and $\mathrm{Cd} 206^{+} \mathrm{M} \varphi \mathrm{s}$. These intermediate cells were mainly present near the branching point or in the branch of the trajectory diverging towards $\mathrm{Cd}_{206}{ }^{+} \mathrm{M} \varphi \mathrm{s}$ and resembled $\mathrm{Ly}_{6 \mathrm{C}} \mathrm{C}^{+} \mathrm{MHCl}{ }^{+}$immature $\mathrm{M} \varphi \mathrm{s}$ characterized by flow cytometry. Furthermore, we identified two main pro-resolving $\mathrm{M} \varphi$ subpopulations during the resolution of muscularis inflammation characterized by $\mathrm{Cd} 206^{+}$ Mhcll $^{\text {hi }}$ and Timp2 $^{+}$Mhcll $^{\text {lo }}$ gene signatures, which are transcriptionally distinct from homeostatic $\mathrm{C} \times 3 \mathrm{cr}^{+}{ }^{+} \mathrm{M} \varphi$ s. Trajectory interference analysis during muscularis inflammation showed that these subpopulations are derived from infiltrating Ly6 $\mathrm{c}^{+}$monocytes. In line, 
bioRxiv preprint doi: https:/doi.org/10.1101/2021.06.10.447700; this version posted June 10, 2021. The copyright holder for this preprint (which was not certified by peer review) is the author/funder, who has granted bioRxiv a license to display the preprint in perpetuity. It is made available under aCC-BY-NC-ND 4.0 International license.

scRNAseq analysis showed that these two myeloid subpopulations are absent from the inflamed muscularis of CCR2 deficient mice, further supporting their monocytic origin. Accordingly, flow cytometric analysis of CX3CR1 ${ }^{\mathrm{GFP} /+}$ mice during muscularis inflammation showed that $\mathrm{CX} 3 \mathrm{CR} 1^{10} \mathrm{MHCII}^{\text {hi }}$ and $\mathrm{CX} 3 \mathrm{CR} 1^{10} \mathrm{MHCll}^{\mathrm{lo}} \mathrm{M} \varphi$ s are derived from $\mathrm{CCR}^{+}$ monocytes and resemble Cd206 ${ }^{+}$and Timp2 ${ }^{+} \mathrm{M} \varphi s$, respectively. Both phenotypically and functionally, Cd206+ Mhcll ${ }^{\text {hi }} \mathrm{M} \varphi s$ showed high resemblance to homeostatic $\mathrm{Cx} 3 \mathrm{cr} 1^{+} \mathrm{M} \varphi s$ with a similar gene signature and activity of specific regulons (e.g. Junb, Irf8) ${ }^{36,37}$, while Timp2 ${ }^{+}$ Mhcll ${ }^{10} \mathrm{M} \varphi s$ displayed an alternative gene signature and regulon activity (e.g. Cebpb, Gata6) ${ }^{38,}$

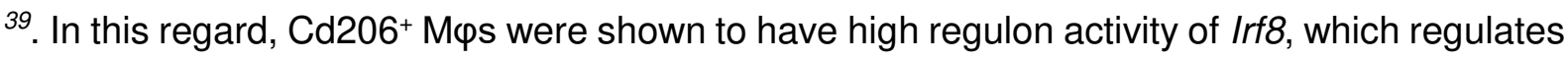
the expression of genes important for the activation of antigen-presenting cells and $\mathrm{T}$ cells (Cd86 and Cd40) and for lymphoid and myeloid chemotaxis (Cxcl9, Cxcl10, Cc/4, Ccl8 and $C c / 12)^{37}$. In addition, these cells upregulated genes involved in efferocytosis and exhibited high Mhcll gene expression. These data indicate that $\mathrm{CD} 206^{+} \mathrm{M} \varphi s$ might respond to apoptotic cells in their vicinity and undergo alternative activation in response to efferocytosis. On the other hand, Timp2 ${ }^{+} M \varphi s$ have high regulon activity of Cebpb, which controls the expression of antiinflammatory genes such as Msr1, I/10, I/13ra, and Arg1. These cells seem to have a high metabolic activity as demonstrated by their GO terms. Studies in small and large peritoneal M $\varphi s$ could be further instrumental in understanding $M \varphi$ biology during muscularis inflammation, as these cells resemble $\mathrm{Cd} 206^{+}$and Timp2 ${ }^{+} \mathrm{M} \varphi s$, respectively, based on gene expression and regulon activity ${ }^{40,41}$. Furthermore, we also found other subpopulations that were characterized by highly specific gene signatures and regulon activities, such as Fabp5 ${ }^{+}$ M $\varphi s$ with enhanced $N r 1 h 3(L X R \alpha)$ and Ppary regulon activity, which may be involved in iron handling (Flt1, Fth1, Hmox1) and detoxification (Mt1, Akr1a1, Prdx1, Cd36). Further studies will be essential to unravel the functional roles of different $M \varphi$ subsets during muscularis inflammation by defining their precise tissue localization and assessing their contribution to the pathophysiological response during local tissue damage.

The muscularis microenvironment is mainly regulated by the ENS, which is composed of a network of enteric neurons and EGCs. Here, M $\varphi s$ are essential to support neuronal function 
via the secretion of BMP- $2^{1,6}$, while neurons in turn produce CSF1, vital for M $\varphi$ development ${ }^{6}$. In addition, CSF1 production has also recently been identified in EGCs ${ }^{19}$. This close neuroimmune interaction between the tissue microenvironment and $M \varphi s$ at homeostasis and during disease is also found in other neuronal tissue niches. For instance, in the central nervous system, there is extensive crosstalk between astrocytes and microglia, critical for brain homeostasis $^{42}$. Upon brain injury, microglia are the first cells to be recruited to the site of damage to phagocytose dead cells and debris ${ }^{43}$, similar to what is observed during muscularis inflammation ${ }^{11,28}$. Concurrently, reactive astrocytes are activated to release pro-inflammatory mediators that affect microglia and can recruit different leukocytes. Subsequently, they increase their expression of GFAP and undergo morphological changes leading to the formation of glial scars ${ }^{44}$. Similarly, we have shown a comparable process taking place at the level of the ENS, in which damage-activated EGCs closely interact with M $\varphi s$ in the muscularis and act as safeguards of the microenvironment by initiating an inflammatory response via CCL2 to protect the tissue from further damage. As opposed to the detrimental effects of astrocytes in brain injury, EGCs induce monocyte differentiation towards pro-resolving CD206+ $\mathrm{M} \varphi \mathrm{s}$ by the production of CSF1, which seems to be important for the resolution of ENS damage as M $M$ s are able to stimulate EGC proliferation. Similarly, upon $M \varphi$ depletion, red pulp fibroblasts transiently produce the monocyte chemoattractants CSF1, CCL2 and CCL7, thereby contributing to monocyte replenishment ${ }^{45}$. Recently, it was also shown that during experimental autoimmune encephalomyelitis, astrocytes provide soluble signals to proinflammatory $M \varphi s$ to induce an anti-inflammatory phenotype ${ }^{46}$.

Overall, these insights may give rise to novel therapeutic approaches to treat patients affected by intestinal inflammatory disorders to avoid complications related to alterations of the ENS and reduced GI motility. Our findings on the impact of anti-inflammatory signals from EGCs on myeloid cells could be extrapolated beyond the context of the intestinal inflammation and may be valuable in the context of several other acute and chronic inflammatory conditions and autoimmune diseases. 
Acknowledgments: The authors would like to thank Iris Appeltans, Naomi Fabre, Tine Gommers and Karlien Vranken (TARGID, KU Leuven) for their technical assistance, and Pier Andrée Penttila and Reena Chinnaraj (FACS Core, KU Leuven) for their assistance with flow cytometry and sorting, the GIGA-Genomics platform (University of Liège) for their assistance in our scRNAseq experiments. Images were recorded at the Cell and Tissue Imaging Cluster (KU Leuven) using a Zeiss LSM 880 - Airyscan (supported by Hercules AKUL/15/37_GOH1816N and FWO G.0929.15 to Pieter Vanden Berghe) and a Zeiss LSM 780 - SP Mai Tai HP DS (supported by Hercules AKUL/11/37 and FWO G.0929.15 to Pieter Vanden Berghe). BioRender was used for making graphical images.

Grant support: M.S. was supported by a PhD fellowship from the FWO-Research Foundation - Flanders (1186317N). V.D.S. was supported by a postdoctoral fellowship in Fundamental Research by the Stichting tegen Kanker. G.G. was supported by a postdoctoral research fellowship of FWO. S.I. was supported by a MSCA-IF (79756-GLIAMAC) and a fellowship from the European Crohn's and Colitis Organization (ECCO). G.M.'s lab was supported by FWO grants G0D8317N, G0A7919N, G086721N and S008419N, a grant from the KU Leuven Internal Funds (C12/15/016 and $\mathrm{C} 14 / 17 / 097$ and from the International Organization for the Study of Inflammatory Bowel Diseases (IOIBD) as well as a research grant from ECCO.

Author contributions: G.M. and S.I. conceptualized this study; S.I. and M.S. designed the experiments; M.S., S.A., V.D.S., G.G., N.S. L.V.B., Q.W., D.P., J.K., L.M., I.P. and S.T. performed the experiments; analyzed data; M.S., S.A., S.I. and G.M. interpreted data; L.B., J.V.G., J.T., S.J. and T.M. provided vital reagents; M.H., P.V., J.V.G., G.B., J.T., S.J. and T.M. gave technical support and conceptual advice, M.S., S.A., S.I. and G.M. contributed to manuscript writing. All authors edited and revised the manuscript.

Conflicts of interest: All authors disclose no conflicts. 


\section{Figure legends}

Figure 1: Identification of CD45+ immune cell populations by unsupervised SCRNAseq clustering in the healthy and inflamed muscularis. A. Experimental pipeline of scRNAseq experiment. B. UMAP of sorted CD45+ immune cells from the healthy muscularis, $24 \mathrm{~h}$ and $72 \mathrm{~h}$ post-injury from WT mice. Each sample was pooled from 3-4 mice. C. Heatmap of the 50 most differentially expressed genes in each cluster. D. UMAPs of time-dependent infiltration of immune cells upon muscularis inflammation. Data of Figure 1B is split out based on different time points. E. Cell fraction of each cluster relative to the total number of CD45+ immune cells at different time points after muscularis inflammation.

Figure 2: Two main anti-inflammatory $M \varphi$ subpopulations with a unique transcriptional state are present during the resolution of muscularis inflammation. A. UMAP of reclustered monocyte/M $\mathrm{M}$ subpopulations from Fig. $1 \mathrm{~A}$ from the healthy muscularis, $24 \mathrm{~h}$ and 72h post-injury from WT mice. B. Heatmap of typical monocyte and $M \varphi$ markers including $\mathrm{MHCIl}$ genes. C. UMAPs of time-dependent infiltration of monocytes/M $\varphi s$ upon muscularis inflammation. D. Cell fraction of each subcluster relative to the total number of monocytes/M $\varphi s$ cells at different time points after muscularis inflammation. E. Dotplot showing expression of selected differentially expressed genes in each subcluster. F. Heatmap of regulon activity per cluster according to SCENIC analysis. G. Pseudotime analysis of monocytes/M $\varphi$ s at different time points after muscularis inflammation. H. Heatmap of gene expression showing the top 50 genes of different branches of the pseudotime trajectory tree.

Figure 3: Two distinct $M \varphi$ subpopulations during the resolution of muscularis inflammation are derived from CCR2 ${ }^{+}$monocytes. A. UMAP of monocyte/M $\varphi$ subclusters from the muscularis of WT and CCR2 ${ }^{---}$mice at $24 \mathrm{~h}$ and $72 \mathrm{~h}$ after induction of muscularis inflammation. Each sample was pooled from 3-4 mice. B. UMAPs of myeloid cells at different time points post-injury. C. Cell fraction of each subcluster relative to the total number of myeloid cells at different time points after muscularis inflammation. D. GO analysis of monocytes versus 


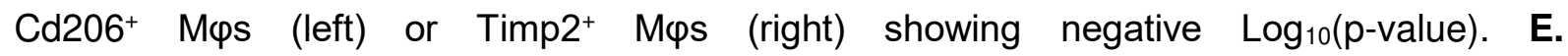
Immunofluorescent images of muscularis whole-mount preparations 3 days after the induction of muscularis inflammation stained for GFAP (purple), TIMP2 (yellow) and CD206 (light blue). Scale bar $15 \mu \mathrm{m}$. F. Experimental outline of in vitro EGC proliferation by stimulation with supernatant of monocytes/M $\varphi s$ from different time points post-injury. Every data point is an independent sorting and culture experiment. G. Fold induction of EGCs stimulated with the supernatant of LY6Chi monocytes from $24 \mathrm{~h}$ post-injury or MHCI ${ }^{\text {hi }} \mathrm{M} \varphi s$ from $72 \mathrm{~h}$ post-injury relative to control medium. One-way ANOVA; test ${ }^{*} \mathrm{p}<0.05 ;{ }^{* *} \mathrm{p}<0.01$; ns=not significant.

Figure 4: Flow cytometry validates unique $M \varphi$ subpopulations during muscularis inflammation. A-H. from naïve $\mathrm{CX} 3 \mathrm{CR} 1^{\mathrm{GFP} /+}$ mice, $24 \mathrm{~h}$ and $72 \mathrm{~h}$ after muscularis inflammation. A. Contour plots representing CX3CR1 expression in Ly6C- MHCI ${ }^{\text {hi }} \mathrm{M} \varphi s$ (left). Percentages and absolute numbers of $\mathrm{CX} 3 \mathrm{CR} 1^{\text {hi }}$ and $\mathrm{CX} 3 \mathrm{CR} 1^{10}$ cells from Ly6C- MHCII ${ }^{\text {hi }} \mathrm{M} \varphi$ s are shown as mean \pm SEM (right). B. Contour plots representing CX3CR1 expression in Ly6C- MHCII M (left). Percentages and absolute numbers of CX3CR $1^{\text {hi }}$ and $\mathrm{CX} 3 \mathrm{CR} 1^{\mathrm{lo}}$ cells from Ly6C- MHCII ${ }^{\text {lo }}$ M $\varphi$ s are shown as mean \pm SEM (right). C-H. CD206 and CCR2 expression in Ly6C- MHCII ${ }^{\text {hi }}$ and $\mathrm{MHCII} / \mathrm{M} \varphi$ s. Contour plots representing CD206 or CCR2 expression in Ly6C- $\mathrm{MHCI}^{\text {hi }}(\mathrm{C})$

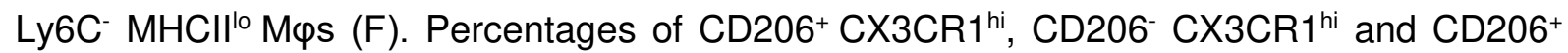
CX3CR $1^{10}$ cells in the LY6C- MHCII ${ }^{\text {hi }} M \varphi s$ (D) and MHCII $M \varphi s(G)$. Percentages of CCR2+ CX3CR $1^{\text {hi }}$, CCR2 $2^{-}$CX3CR $1^{\text {hi }}$ and CCR2 ${ }^{+}$CX $3 C R 1^{\text {lo }}$ cells in the LY6C- MHCII ${ }^{\text {hi }} M \varphi s(E)$ and MHCII ${ }^{\circ} \mathrm{M} \varphi s(H)$. One-way ANOVA; test ${ }^{*} \mathrm{p}<0.05 ;{ }^{* *} \mathrm{p}<0.01$; ns $=$ not significant.

Figure 5: EGCs produce factors essential for the recruitment and differentiation of monocytes during inflammation. A. Relative mRNA levels for $\mathrm{Ccl} 2$ and $\mathrm{Csf1}$ normalized to the housekeeping gene rp/32 from ganglia isolated from the muscularis of the small intestine from naïve wild-type mice and $1.5 \mathrm{~h}, 3 \mathrm{~h}$ and $24 \mathrm{~h}$ after muscularis inflammation. One-way ANOVA; test ${ }^{*} p<0.05 ;{ }^{* *} p<0.01$; ns not significant. B. Immunofluorescent images of muscularis whole-mount preparations at homeostasis and $1.5 \mathrm{~h}$ after the induction of muscularis inflammation stained for GFAP (green), HuC/D (grey) and CCL2 (purple). Scale bar (25x) 25 
$\mu \mathrm{m},(63 \mathrm{x}) 15 \mu \mathrm{m}$. C. Experimental overview of experiments in PLP-CreERT2 Rpl22 ${ }^{\mathrm{HA}}$ mice. D. Heatmap of differentially expressed genes between immunoprecipitated samples from naïve PLP-CreERT2 Rpl22 ${ }^{\mathrm{HA}}$ mice and $3 \mathrm{~h}$ after intestinal manipulation. E. Selected significant GO terms enriched (GSEA) in PLP1+ EGCs 3h post-injury compared to naive PLP1+ EGCs. F. Heat map of ligand-target pairs showing regulatory potential scores between all positively correlated prioritized ligands and their target genes among the differentially expressed genes between $\mathrm{Ly}_{6 \mathrm{c}^{+}}$monocytes and $\mathrm{Ccr}^{+}$int M $\varphi$ s. G. Circos plot showing top NicheNet ligandreceptor pairs between EGCs and Ly6 $\mathrm{c}^{+}$monocytes corresponding to the prioritized ligands in Fig. 5F. H. Schematic overview of interaction between EGCs and infiltrating Ly $6 c^{+}$monocytes.

Figure 6: Enteric glia-derived CSF1 stimulates the differentiation of monocytes into pro-

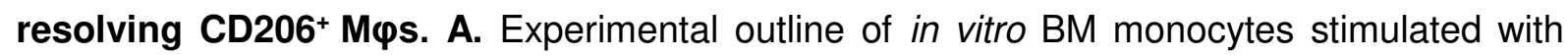
supernatant of EGCs. B. Relative mRNA levels for pro- and anti-inflammatory cytokines normalized to the housekeeping gene rp/32 in BM monocytes cultured for $24 \mathrm{~h}$ with or without EGC supernatant. C. Experimental outline of in vitro experiment using sorted $\mathrm{Ly}_{6 \mathrm{C}} \mathrm{MHCII}^{-}$ monocytes stimulated with EGC supernatant for $24 \mathrm{~h}$. D. Relative mRNA levels for of pro- and anti-inflammatory mediators normalized to the housekeeping gene rp/32 in sorted Ly6C+ $\mathrm{MHCII}^{-}$monocytes stimulated with or without EGC supernatant. E-H. BM monocytes were cultured for 24-48h with/without EGC supernatant and/or supplemented with anti-CSF1r antibody. E. Contour plots of BM monocytes showing expression of CD206 (top) or CCR2 (bottom) upon culture for $48 \mathrm{~h}$ with/without EGC supernatant and supplemented with antiCSF1r antibody. F. Brightfield images of monocytes upon culture for $24 \mathrm{~h}$ with or without EGC supernatant. G. Quantification of $7-A A D^{+}$cells in BM monocytes cultured for $24 \mathrm{~h}-48 \mathrm{~h}$ with/without EGC supernatant or supplemented with anti-CSF1r antibody. H. Percentages of $\mathrm{CD} 11 \mathrm{~b}^{+} \mathrm{CD}^{+} 4^{+}$cells in live CD45 $5^{+}$population, and CCR2 ${ }^{+}$and $\mathrm{CD} 206^{+}$cells in live CD45 CD11b+ Ly6G- CD64+ population. A-D. T-test. G-H. one-way ANOVA. * $p<0.05 ;{ }^{* *} p<0.01$. 


\section{References}

1. Gabanyi I, Muller PA, Feighery L, et al. Neuro-immune Interactions Drive Tissue Programming in Intestinal Macrophages. Cell 2016;164:378-91.

2. Asano K, Takahashi N, Ushiki M, et al. Intestinal CD169(+) macrophages initiate mucosal inflammation by secreting CCL8 that recruits inflammatory monocytes. Nat Commun 2015;6:7802.

3. Hadis $\mathrm{U}, \mathrm{Wahl} \mathrm{B}$, Schulz $\mathrm{O}$, et al. Intestinal tolerance requires gut homing and expansion of FoxP3+ regulatory T cells in the lamina propria. Immunity 2011;34:237-46.

4. Mowat AM. Publisher Correction: To respond or not to respond - a personal perspective of intestinal tolerance. Nat Rev Immunol 2018;18:536.

5. Zigmond E, Bernshtein B, Friedlander G, et al. Macrophage-restricted interleukin-10 receptor deficiency, but not IL-10 deficiency, causes severe spontaneous colitis. Immunity 2014;40:72033.

6. Muller PA, Koscso B, Rajani GM, et al. Crosstalk between muscularis macrophages and enteric neurons regulates gastrointestinal motility. Cell 2014;158:300-313.

7. De Schepper S, Verheijden S, Aguilera-Lizarraga J, et al. Self-Maintaining Gut Macrophages Are Essential for Intestinal Homeostasis. Cell 2018;175:400-415 e13.

8. Kalff JC, Turler A, Schwarz NT, et al. Intra-abdominal activation of a local inflammatory response within the human muscularis externa during laparotomy. Ann Surg 2003;237:30115.

9. de Jonge WJ, van den Wijngaard RM, The FO, et al. Postoperative ileus is maintained by intestinal immune infiltrates that activate inhibitory neural pathways in mice. Gastroenterology 2003;125:1137-47.

10. Wehner S, Behrendt FF, Lyutenski BN, et al. Inhibition of macrophage function prevents intestinal inflammation and postoperative ileus in rodents. Gut 2007;56:176-85.

11. Farro G, Stakenborg M, Gomez-Pinilla PJ, et al. CCR2-dependent monocyte-derived macrophages resolve inflammation and restore gut motility in postoperative ileus. Gut 2017;66:2098-2109.

12. Savidge TC, Sofroniew MV, Neunlist M. Starring roles for astroglia in barrier pathologies of gut and brain. Lab Invest 2007;87:731-6.

13. Neunlist M, Rolli-Derkinderen $M$, Latorre R, et al. Enteric glial cells: recent developments and future directions. Gastroenterology 2014;147:1230-7.

14. Bach-Ngohou K, Mahe MM, Aubert P, et al. Enteric glia modulate epithelial cell proliferation and differentiation through 15-deoxy-12,14-prostaglandin J2. J Physiol 2010;588:2533-44.

15. Coelho-Aguiar Jde M, Bon-Frauches AC, Gomes AL, et al. The enteric glia: identity and functions. Glia 2015;63:921-35.

16. Bassotti $G$, Villanacci $V$, Antonelli $E$, et al. Enteric glial cells: new players in gastrointestinal motility? Lab Invest 2007;87:628-32.

17. Ibiza S, Garcia-Cassani B, Ribeiro H, et al. Glial-cell-derived neuroregulators control type 3 innate lymphoid cells and gut defence. Nature 2016;535:440-443.

18. Vainchtein ID, Molofsky AV. Astrocytes and Microglia: In Sickness and in Health. Trends Neurosci 2020;43:144-154.

19. Grubisic V, McClain JL, Fried DE, et al. Enteric Glia Modulate Macrophage Phenotype and Visceral Sensitivity following Inflammation. Cell Rep 2020;32:108100.

20. Boring L, Gosling J, Chensue SW, et al. Impaired monocyte migration and reduced type 1 (Th1) cytokine responses in C-C chemokine receptor 2 knockout mice. J Clin Invest 1997;100:255261.

21. Jung S, Aliberti J, Graemmel P, et al. Analysis of fractalkine receptor CX(3)CR1 function by targeted deletion and green fluorescent protein reporter gene insertion. Mol Cell Biol 2000;20:4106-14. 
22. Yona $\mathrm{S}$, Kim $\mathrm{KW}$, Wolf $\mathrm{Y}$, et al. Fate mapping reveals origins and dynamics of monocytes and tissue macrophages under homeostasis. Immunity 2013;38:79-91.

23. Srinivas $S$, Watanabe $T$, Lin CS, et al. Cre reporter strains produced by targeted insertion of EYFP and ECFP into the ROSA26 locus. BMC Dev Biol 2001;1:4.

24. Doerflinger NH, Macklin WB, Popko B. Inducible site-specific recombination in myelinating cells. Genesis 2003;35:63-72.

25. Sanz E, Yang L, Su T, et al. Cell-type-specific isolation of ribosome-associated mRNA from complex tissues. Proc Natl Acad Sci U S A 2009;106:13939-44.

26. van Bree SH, Nemethova A, van Bovenkamp FS, et al. Novel method for studying postoperative ileus in mice. Int J Physiol Pathophysiol Pharmacol 2012;4:219-27.

27. Aran $\mathrm{D}$, Looney $\mathrm{AP}$, Liu L, et al. Reference-based analysis of lung single-cell sequencing reveals a transitional profibrotic macrophage. Nat Immunol 2019;20:163-172.

28. Desalegn $G$, Pabst $O$. Inflammation triggers immediate rather than progressive changes in monocyte differentiation in the small intestine. Nat Commun 2019;10:3229.

29. Qiu $X$, Mao $Q$, Tang $Y$, et al. Reversed graph embedding resolves complex single-cell trajectories. Nat Methods 2017;14:979-982.

30. Shi C, Pamer EG. Monocyte recruitment during infection and inflammation. Nat Rev Immunol 2011;11:762-74.

31. Haimon Z, Volaski A, Orthgiess J, et al. Re-evaluating microglia expression profiles using RiboTag and cell isolation strategies. Nat Immunol 2018;19:636-644.

32. Kim JS, Kolesnikov M, Peled-Hajaj S, et al. A Binary Cre Transgenic Approach Dissects Microglia and CNS Border-Associated Macrophages. Immunity 2021;54:176-190 e7.

33. Liddelow SA, Guttenplan KA, Clarke LE, et al. Neurotoxic reactive astrocytes are induced by activated microglia. Nature 2017;541:481-487.

34. Browaeys R, Saelens $W$, Saeys $Y$. NicheNet: modeling intercellular communication by linking ligands to target genes. Nat Methods 2020;17:159-162.

35. Mich JK, Signer RA, Nakada D, et al. Prospective identification of functionally distinct stem cells and neurosphere-initiating cells in adult mouse forebrain. Elife 2014;3:e02669.

36. Fontana MF, Baccarella A, Pancholi N, et al. JUNB is a key transcriptional modulator of macrophage activation. J Immunol 2015;194:177-86.

37. Langlais $D$, Barreiro LB, Gros $P$. The macrophage IRF8/IRF1 regulome is required for protection against infections and is associated with chronic inflammation. J Exp Med 2016;213:585-603.

38. Ruffell D, Mourkioti F, Gambardella A, et al. A CREB-C/EBPbeta cascade induces M2 macrophage-specific gene expression and promotes muscle injury repair. Proc Natl Acad Sci U S A 2009;106:17475-80.

39. Rosas M, Davies LC, Giles PJ, et al. The transcription factor Gata6 links tissue macrophage phenotype and proliferative renewal. Science 2014;344:645-648.

40. Ghosn EE, Cassado AA, Govoni GR, et al. Two physically, functionally, and developmentally distinct peritoneal macrophage subsets. Proc Natl Acad Sci U S A 2010;107:2568-73.

41. Cain DW, O'Koren EG, Kan MJ, et al. Identification of a tissue-specific, C/EBPbeta-dependent pathway of differentiation for murine peritoneal macrophages. J Immunol 2013;191:4665-75.

42. Matejuk A, Ransohoff RM. Crosstalk Between Astrocytes and Microglia: An Overview. Front Immunol 2020;11:1416.

43. Hanisch UK, Kettenmann $\mathrm{H}$. Microglia: active sensor and versatile effector cells in the normal and pathologic brain. Nat Neurosci 2007;10:1387-94.

44. Sofroniew MV. Astrogliosis. Cold Spring Harb Perspect Biol 2014;7:a020420.

45. Bellomo A, Mondor I, Spinelli L, et al. Reticular Fibroblasts Expressing the Transcription Factor WT1 Define a Stromal Niche that Maintains and Replenishes Splenic Red Pulp Macrophages. Immunity 2020;53:127-142 e7.

46. Locatelli G, Theodorou D, Kendirli A, et al. Mononuclear phagocytes locally specify and adapt their phenotype in a multiple sclerosis model. Nat Neurosci 2018;21:1196-1208. 


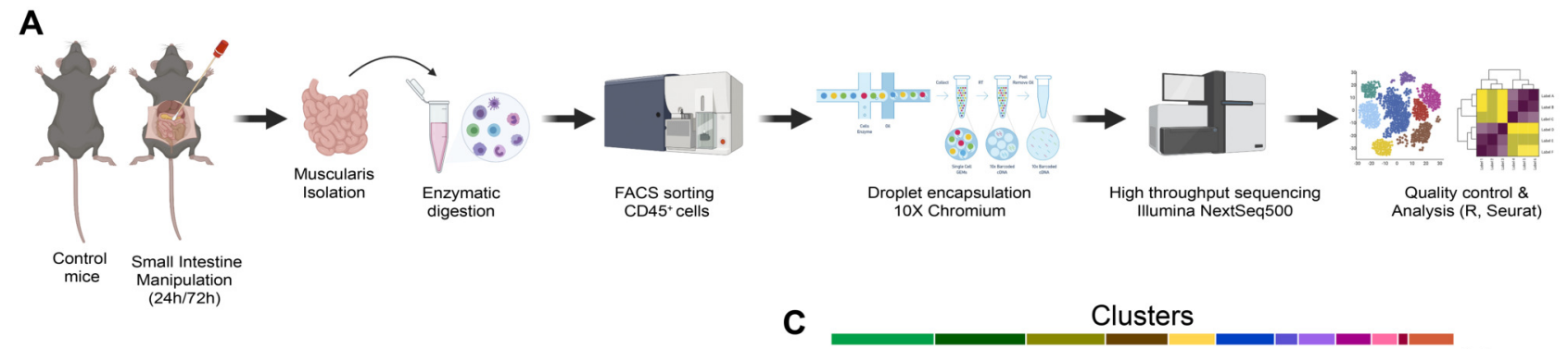

B
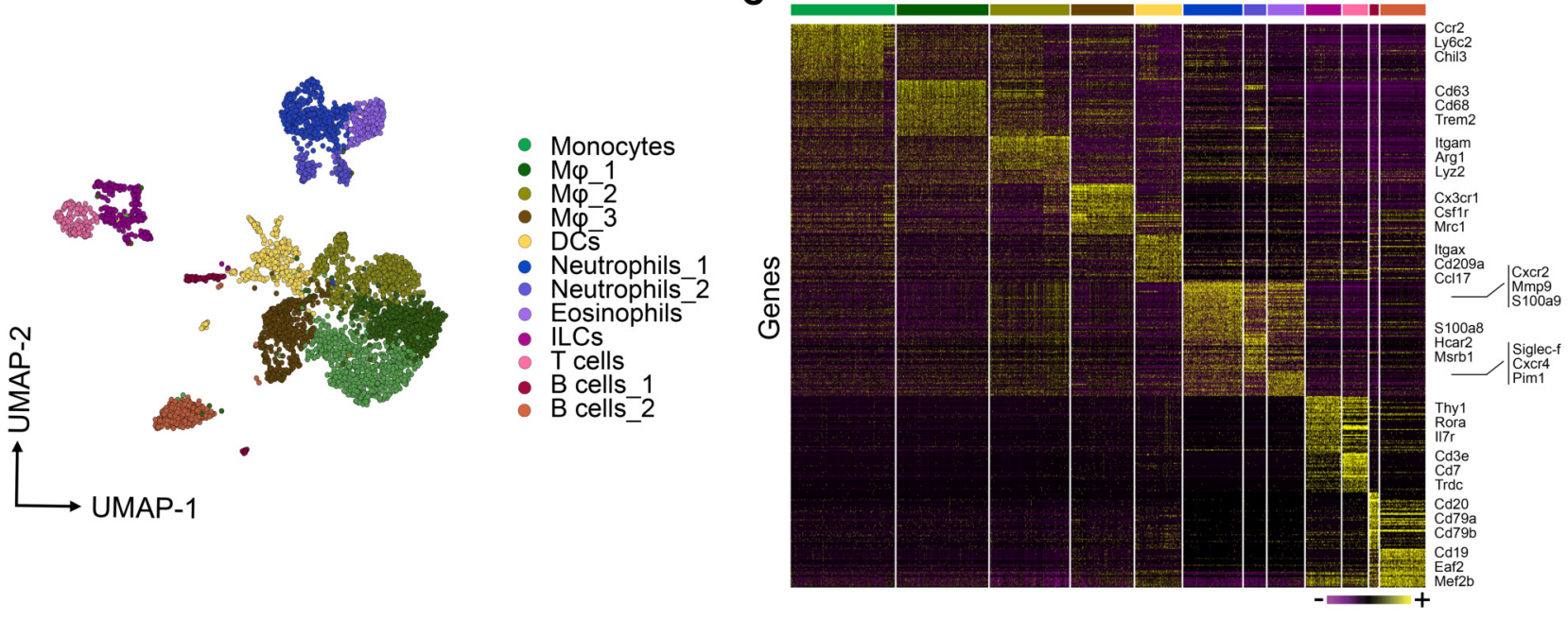

D

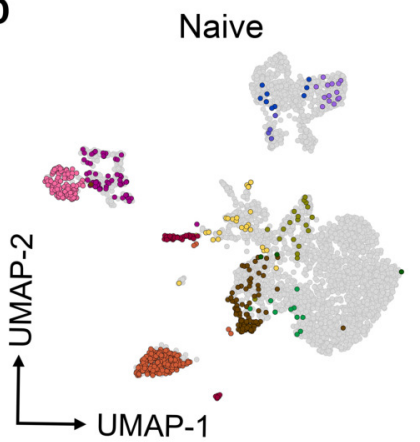

$24 \mathrm{~h}$

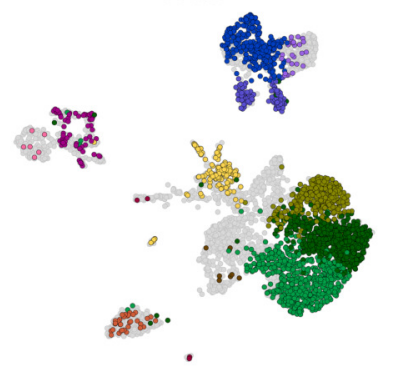

$72 \mathrm{~h}$

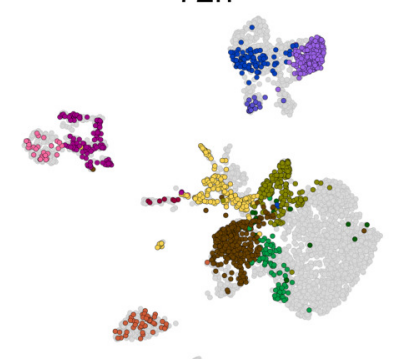

E

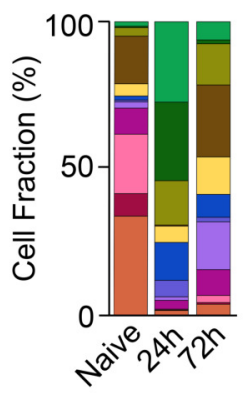

Fig_1 
A

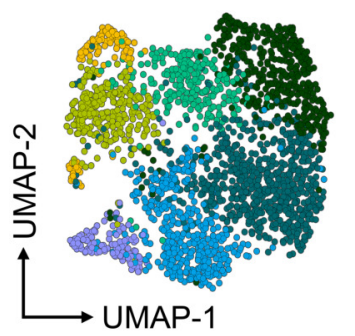

C

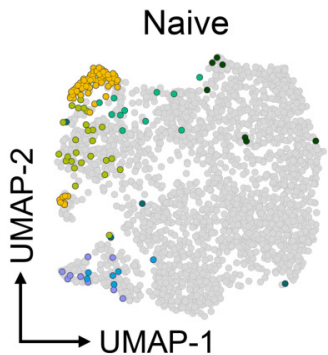

E

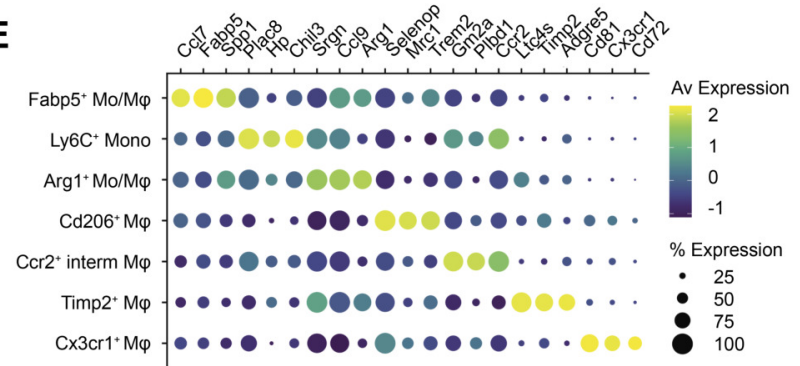

$\mathrm{Fabp}^{+} \mathrm{Mo} / \mathrm{M} \varphi$

- Ly6c ${ }^{+}$Mono

- $\operatorname{Arg} 1^{+} \mathrm{Mo} / \mathrm{M \varphi}$

$\mathrm{Cd} 206^{+} \mathrm{M} \varphi$

- $\mathrm{Ccr} 2^{+}$interm M $\varphi$

Timp2 $2^{+} \varphi$

$\mathrm{C} \times 3 \mathrm{Cr}^{1+} \mathrm{M} \varphi$

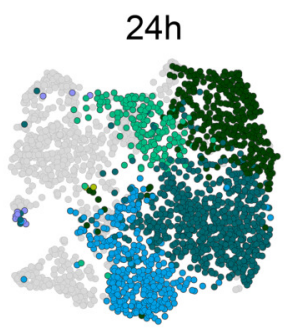

B

G
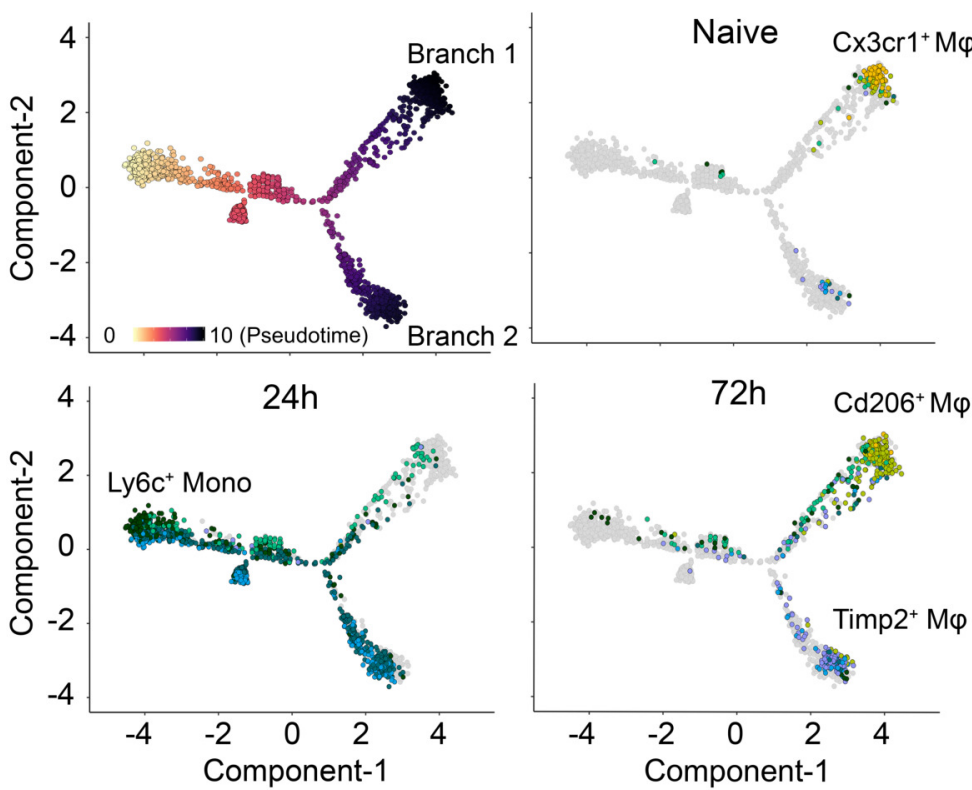

$\mathrm{Cd} 206^{+} \mathrm{M} \varphi$

Timp2 ${ }^{+} \mathrm{M \varphi}$

$\mathrm{Ccr}^{+}$interm $\mathrm{M} \varphi$

$\mathrm{Arg} 1^{+} \mathrm{Mo} / \mathrm{M} \varphi$

$\mathrm{Fabp}^{+} \mathrm{Mo} / \mathrm{M} \varphi$

Ly $6 \mathrm{c}^{+}$Mono

$\mathrm{C} \times 3 \mathrm{Cr}^{1+} \mathrm{Me}$

D

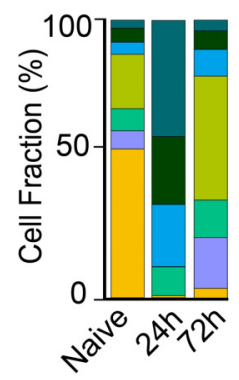

F

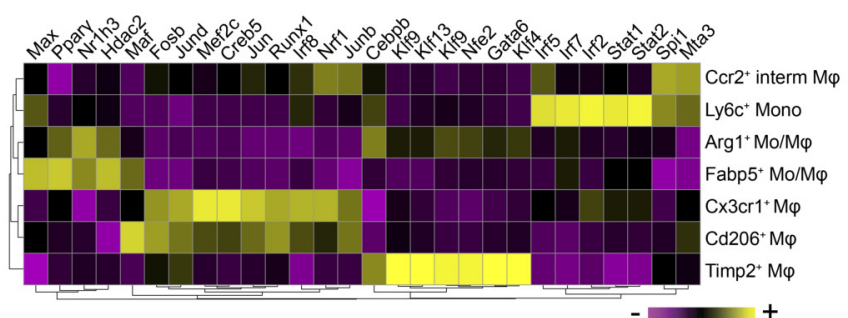

H

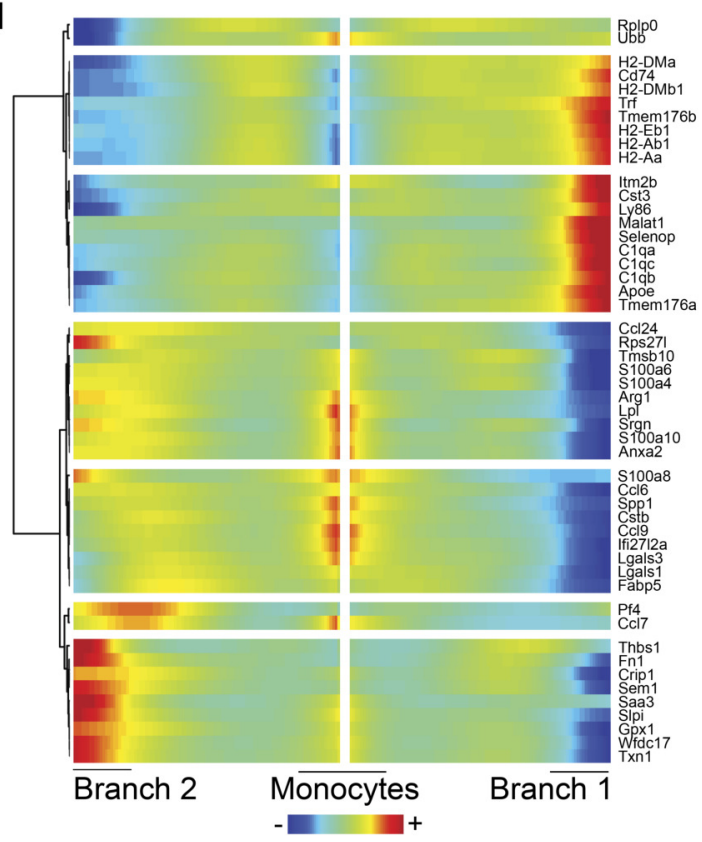


A

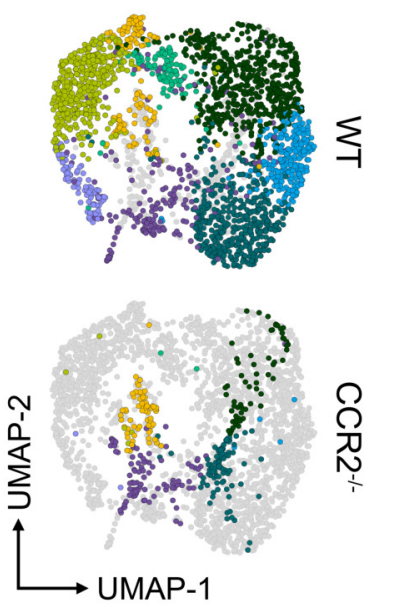

B

- $\mathrm{Fabp}^{+} \mathrm{Mo} / \mathrm{M \varphi}$

- $\mathrm{Fn}^{+} \mathrm{Mo} / \mathrm{M \varphi}$

- Arg 1+ Mo/M $\varphi$

- Ly6c ${ }^{+}$Mono

- $\mathrm{Cd}_{206}{ }^{\mathrm{M}} \varphi$

- $\mathrm{Ccr}^{+}{ }^{+}$interm M $\varphi$

- Timp $2^{+} M \varphi$

- $\mathrm{C} 3 \mathrm{Cr}^{+} \mathrm{M} \varphi$
D

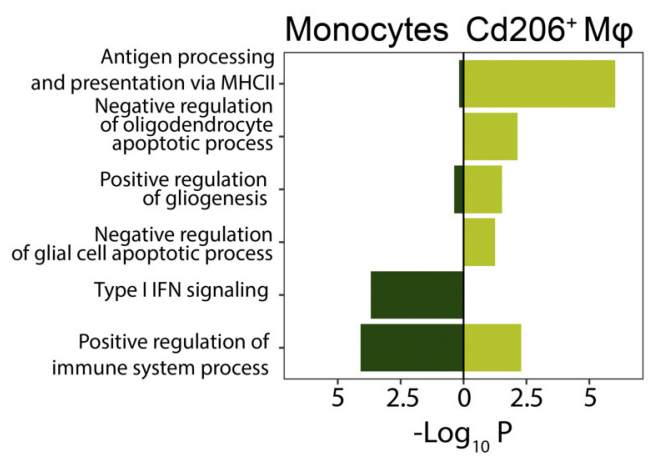

E
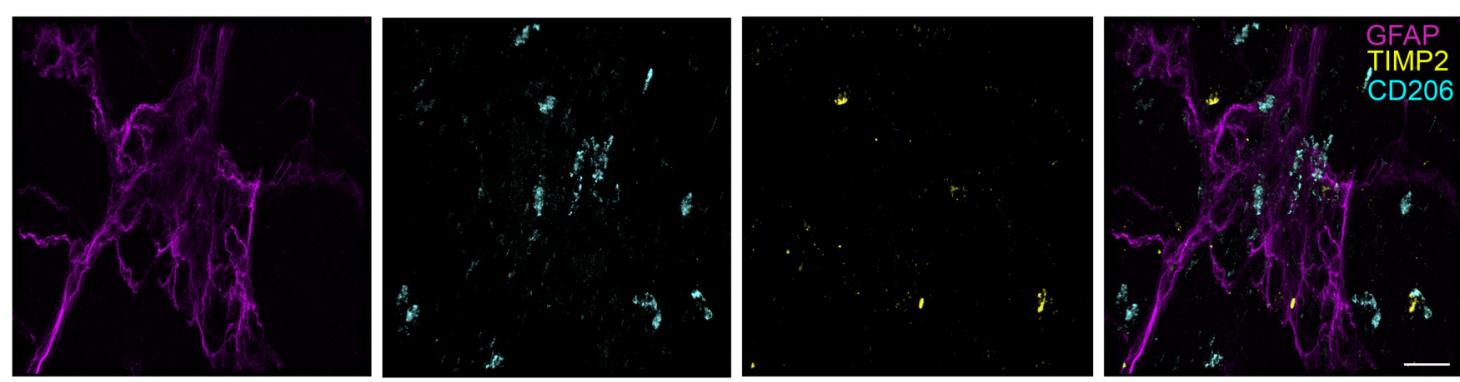

F

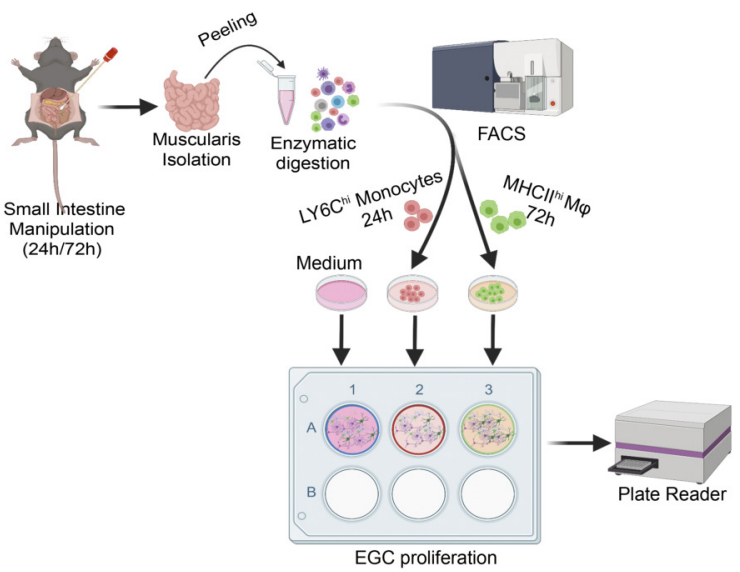

G

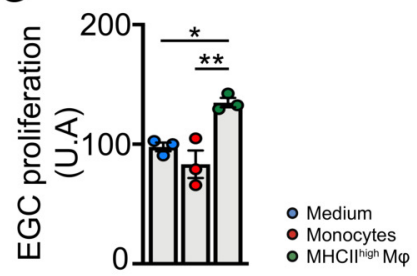

Fig_3 
A Live CD45+ CD11 $\mathrm{b}^{+}$Ly6G- CD64+Ly6C-MHCII high
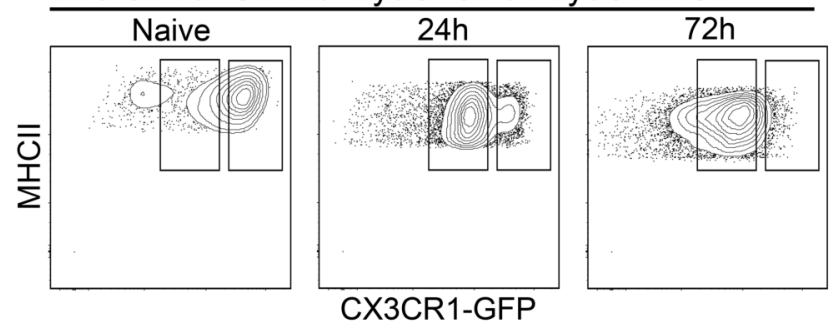

B Live CD45 ${ }^{+}$CD11 $b^{+}$Ly6G- CD64+Ly6C-MHCIILow
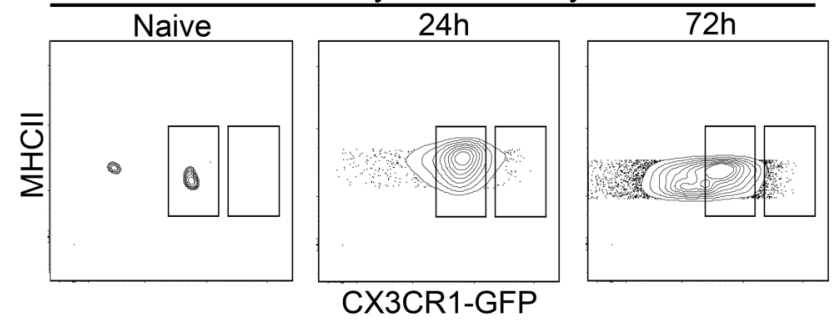

C Live CD45 ${ }^{+}$CD11 b+ Ly6G- CD64+Ly6C-MHCIIhigh
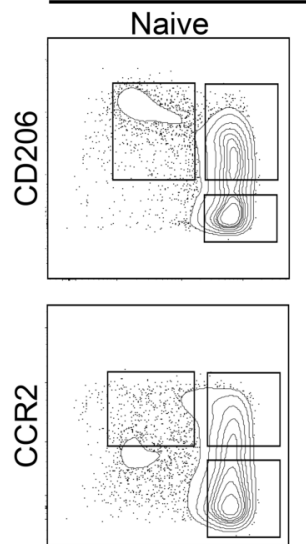

D
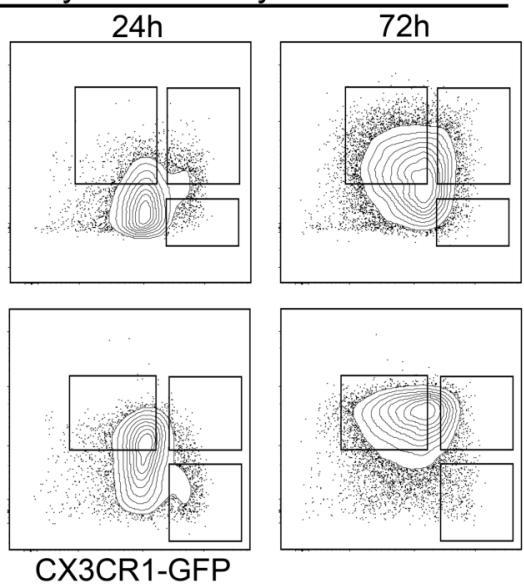

E$$
\text { E }
$$
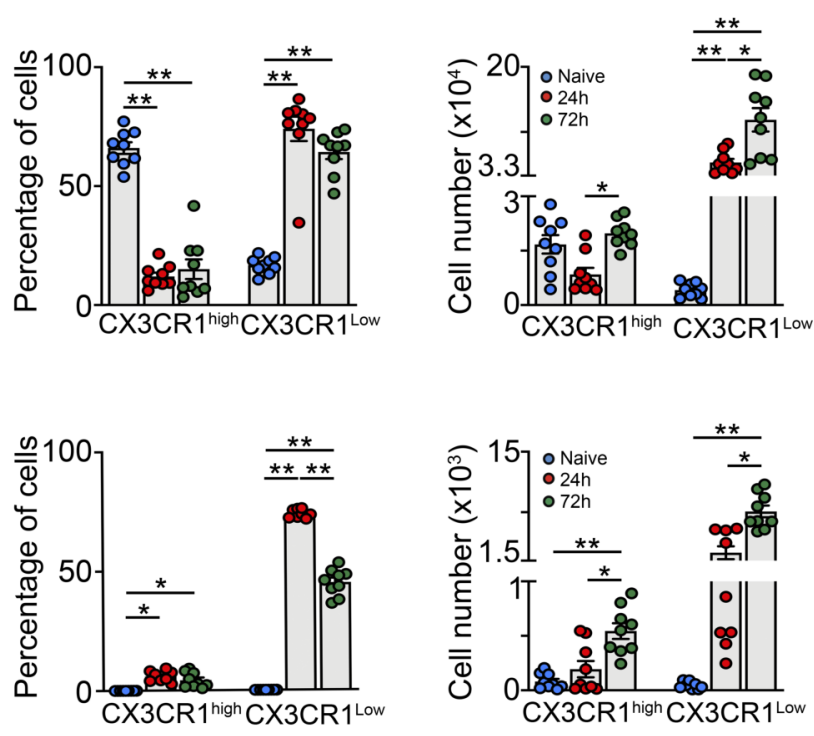

F Live CD45 ${ }^{+}$CD11 b $\mathrm{b}^{+}$Ly6G- CD64+Ly6C-MHCII Low
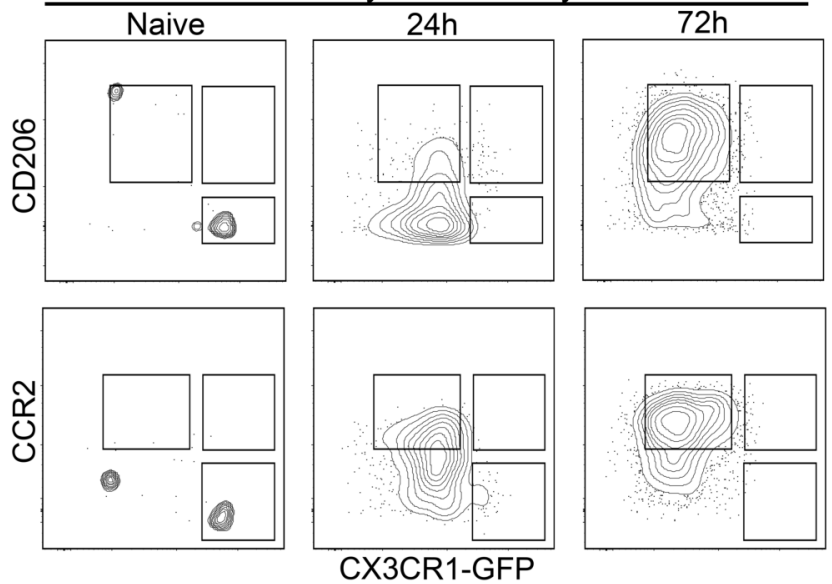

G

$\mathbf{H}$
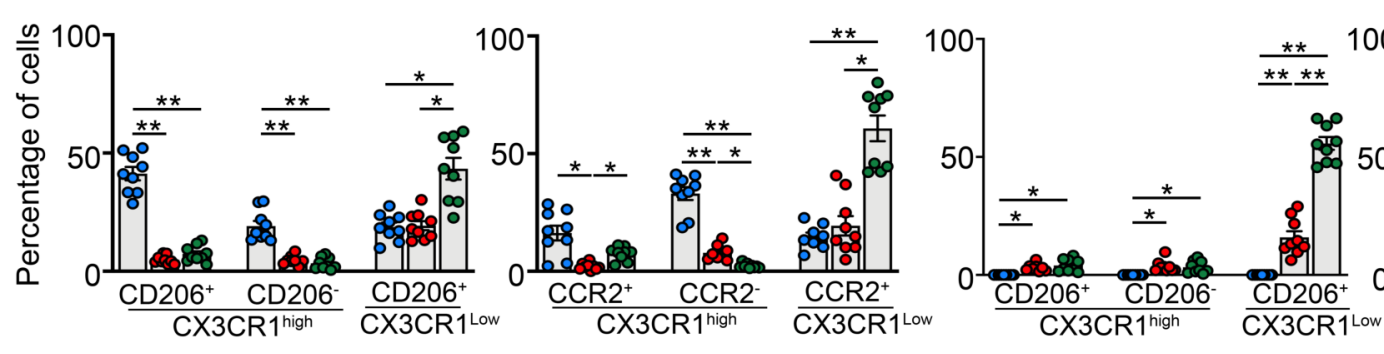

H 
A

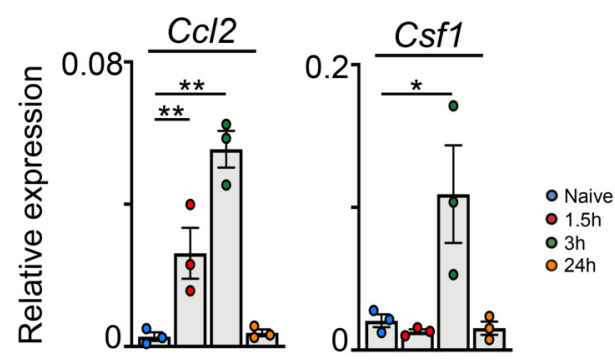

B

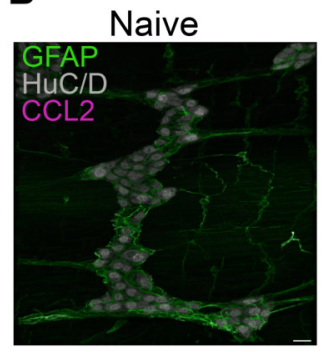

$1.5 \mathrm{~h}$

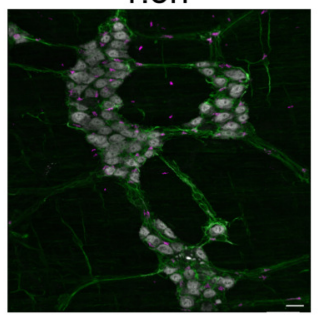

$1.5 h(63 x)$

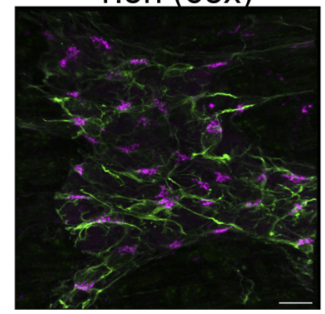

C

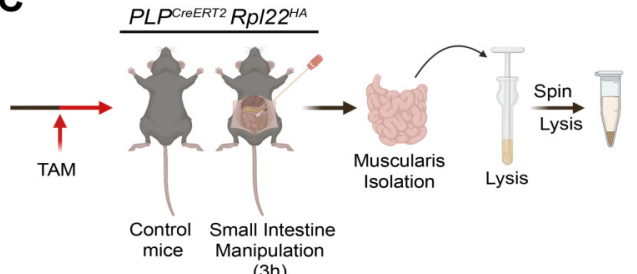
(3h)

E

Response to reactive oxygen speciesRegulation of myeloid cell differentiationRegulation of cytokine productionPositive regulation of cell proliferationNegative regulation of cell deathNegative regulation of apoptotic signaling pathwayPositive regulation of cell differentiationPositive regulation of immune system process-

$\mathbf{F}$

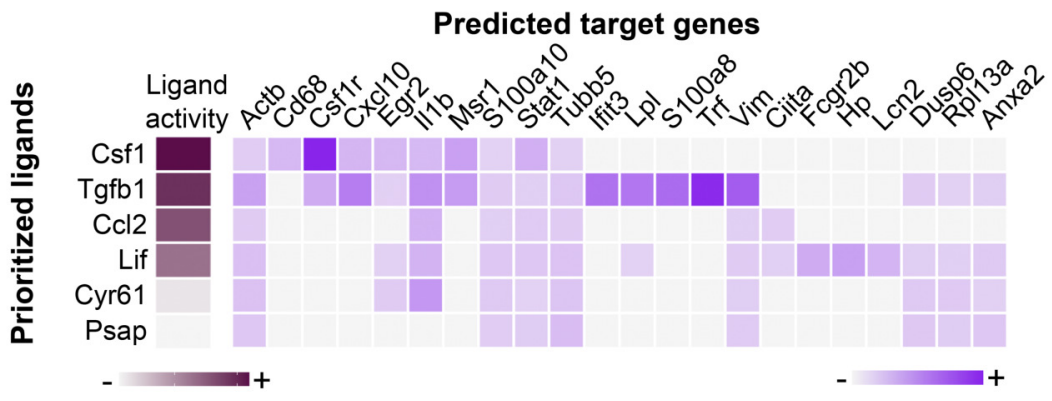

H

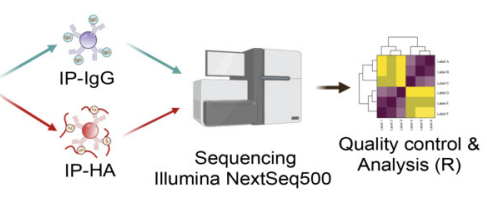

D

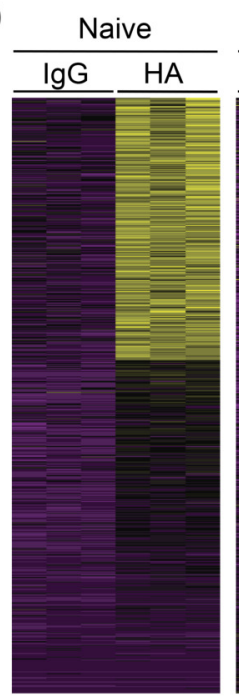
$\frac{3 h}{\lg G \quad H A}$

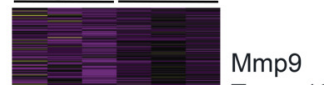

Tmem100

Kcna2

Wnt6

G

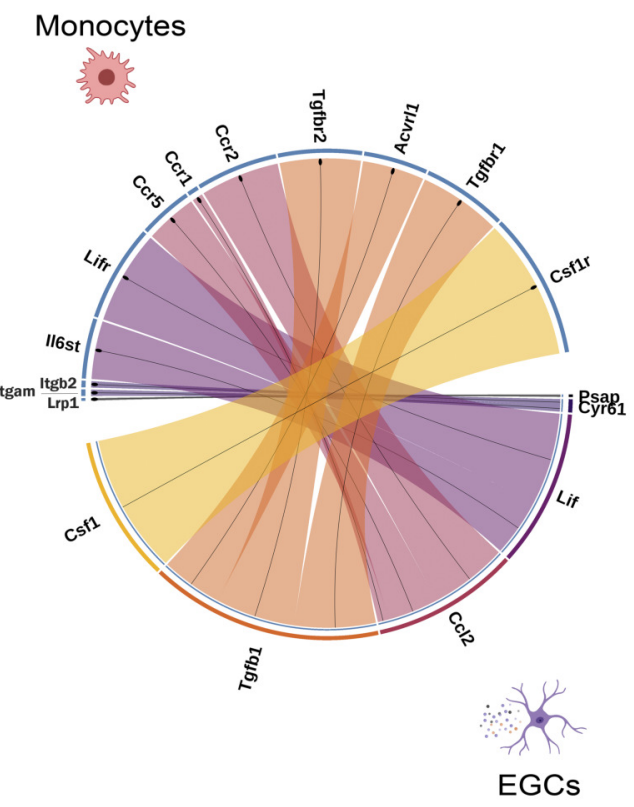


A

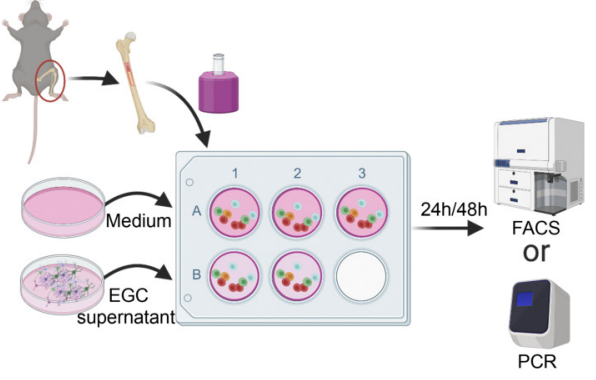

C

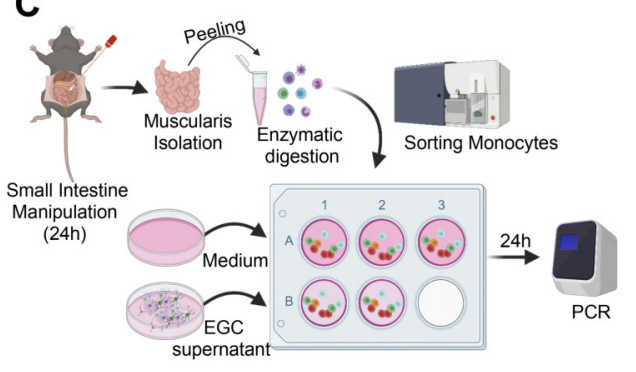

E
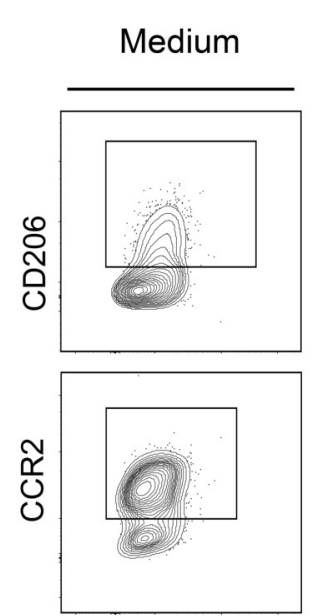

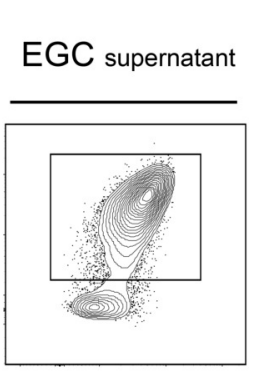

CD64

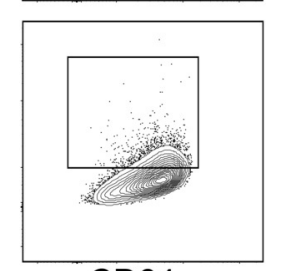

B

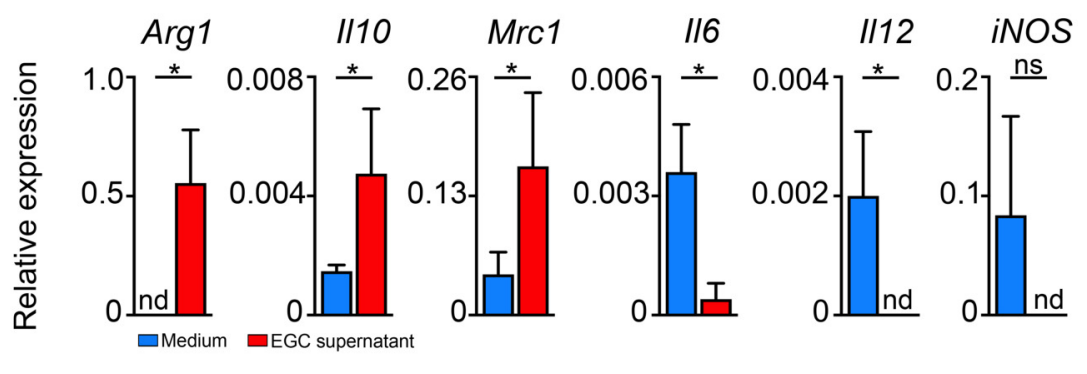

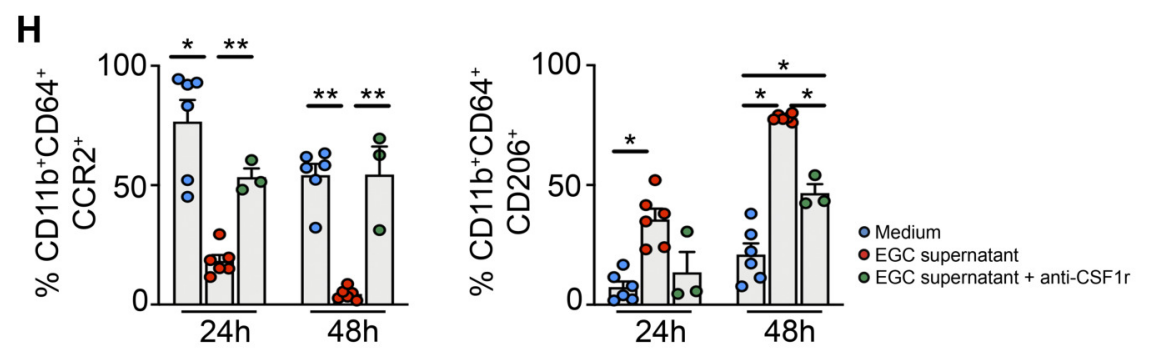

Fig_6 


\section{Supplementary information:}

\section{Enteric glial cells favour accumulation of anti-inflammatory macrophages during the resolution of muscularis inflammation}

Short title: EGC-M $\varphi$ interaction in muscularis inflammation

Michelle Stakenborg1, \#, Saeed Abdurahiman", \#, Veronica De Simone1, Gera Goverse ${ }^{1}$, Nathalie Stakenborg ${ }^{1}$, Lies van Baarle ${ }^{1}$, Qin Wu ${ }^{1}$, Dimitri Pirottin², Jung-Seok Kim³ ${ }^{3}$, Louise Chappell-Maor ${ }^{3}$, Isabel Pintelon ${ }^{4}$, Sofie Thys ${ }^{4}$, Louis Boon ${ }^{5}$, Marlene Hao ${ }^{1}$, Jo A. Van Ginderachter ${ }^{6,7}$, Guy E. Boeckxstaens ${ }^{1}$, Jean-Pierre Timmermans ${ }^{4}$, Steffen Jung ${ }^{3}$, Thomas Marichal ${ }^{8,9}$, Sales Ibiza ${ }^{1,4, *}$, Gianluca Matteoli ${ }^{1, *}$

\section{Affiliation}

${ }^{1}$ Department of Chronic Diseases, Metabolism and Ageing (CHROMETA), Translational Research Center for Gastrointestinal Disorders (TARGID), KU Leuven, Leuven, Belgium.

'Laboratory of Cellular and Molecular Immunology, GIGA Institute, Liege University, Liege, Belgium.

${ }^{3}$ Department of Immunology, Weizmann Institute of Science, Rehovot, Israel.

${ }^{4}$ Laboratory of Cell Biology \& Histology, Department of Veterinary Sciences, University of Antwerp, Antwerp, Belgium.

${ }^{5}$ Polpharma Biologics, Utrecht, the Netherlands.

${ }^{6}$ Cellular and Molecular Immunology Lab, Department of Bio-engineering Sciences, Vrije Universiteit Brussel, Brussels, Belgium.

${ }^{7}$ Myeloid Cell Immunology Lab, VIB Center for Inflammation Research, Brussels, Belgium.

${ }^{8}$ Laboratory of Immunophysiology, GIGA Institute, Liege University, Liege, Belgium.

${ }^{9}$ Department of functional sciences, Faculty of Veterinary Medicine, Liege University, Liege, Belgium.

\#, these authors contributed equally to this work.

*, senior authors: Sales Ibiza and Gianluca Matteoli

\section{Corresponding author:}

Prof. Sales Ibiza, PhD

Laboratory of Cell Biology \& Histology

Department of Veterinary Sciences University of Antwerp,

Campus Drie Eiken, Universiteitsplein 1, B-2610 Wilrijk, Belgium

$\mathrm{T}+32-3-2653324$

Email: Sales.IbizaMartinez@uantwerpen.be

Prof. Gianluca Matteoli, DVM, PhD

Laboratory of Mucosal Immunology

Department of Chronic Diseases, Metabolism and Ageing (CHROMETA)

KU Leuven, Herestraat 49, O\&N1 box 701| BE-3000 Leuven | Belgium

Tel. + $32(0) 16377566$

Email: gianluca.matteoli@kuleuven.be 


\section{Supplementary methods:}

Immunofluorescence. The small intestine was removed and flushed with ice-cold PBS to remove luminal contents. Then, the intestine was cut open longitudinally before stretching and was fixed for $30 \mathrm{~min}$ in $4 \%$ PFA at room temperature. Next, the tissue was washed three times with PBS and the mucosa and submucosa were removed with a forceps to obtain wholemounts of the muscularis, after which it was permeabilized and blocked in $0.3 \%$ Triton X-100 and 3\% BSA in PBS for $2 \mathrm{~h}$ at room temperature. Subsequently, samples were incubated for $48 \mathrm{~h}$ at $4^{\circ} \mathrm{C}$ with the following primary antibodies: chicken anti-neurofilament (Abcam; ab72996), rat anti-GFP (Nacalai Tesque; GF090R), goat anti-CCL2 (R\&D Systems; AF-479NA), rabbit anti-GFAP (Dako; Z0334), chicken anti-GFAP (Abcam; ab4674), goat anti-TIMP2 (R\&D systems, AF971), rabbit anti-CD206 (Abcam, ab64693), rabbit anti-HA (CST; Rb\#3724), human ANNA-1 serum anti-HuC/D (kindly provided by Prof. Lennon V. A. (Mayo Clinic, Rochester, Minnesota, USA) ${ }^{1}$. Afterwards, samples were washed in PBS and incubated with DAPI (4',6-Diamidine-2'-phenylindole dihydrochloride; Sigma-Aldrich) combined with the secondary antibodies: donkey anti-chicken Cy5 (Jackson), donkey anti-rat Alexa Fluor 488 (Invitrogen), donkey anti-rabbit Cy3 (Jackson), donkey anti-human Cy5 (Jackson) and donkey anti-rabbit FITC. All primary and secondary antibodies were dissolved in $0.3 \%$ Triton X-100 and $3 \%$ BSA in PBS. Finally, samples were rinsed three times in PBS and mounted with SlowFade Diamond Antifade mountant (Invitrogen). Images were recorded on a LSM780 or LSM880 multiphoton microscope (Zeiss) and a $25 x$ or $63 x$ objective (Zeiss) was used. Identical settings were used for all conditions in one experiment. Images were processed and analyzed using ImageJ (NIH) or Imaris software (Bitplane).

Lineage Tracing of CX3CR1+ Macrophages. To induce CreERT2 recombinase activity to

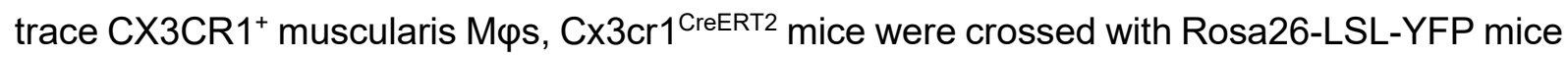
to obtain double heterozygous mice. Mice aged 8 weeks were injected three times subcutaneously with $4 \mathrm{mg}$ TAM (Sigma-Aldrich, St. Louis, USA) per $30 \mathrm{~g}$ body weight dissolved in corn oil (Sigma-Aldrich) every other day as previously described ${ }^{2}$. Mice were sacrificed 4 weeks after the first tamoxifen injection. 
Isolation and digestion of the muscularis. The small intestine was removed and flushed with ice-cold PBS. The muscularis was carefully removed with a forceps, cut in small pieces with scissors and digested in $2 \mathrm{mg} / \mathrm{mL}$ collagenase type IV (Gibco) in RPMI-1640 (Lonza) supplemented with $2 \%$ HEPES (Gibco), $2 \%$ FBS and $5 \mathrm{U} / \mathrm{mL}$ DNase I (Roche) for 30 min at $37^{\circ} \mathrm{C}$ with continuous stirring. The resulting cell suspension was blocked using FACS buffer and passed through a $70 \mu \mathrm{m}$ cell strainer (BD Falcon), after which cells were spun down at $400 \times \mathrm{g}$ for $8 \mathrm{~min}$ at $4^{\circ} \mathrm{C}$. Cells were counted using the Countess II FL (Thermo Fisher).

Flow Cytometry and Sorting of Live Cells. Single cell suspensions were blocked with rat anti-mouse CD16/CD32 (Fc block, BD Biosciences) for $10 \mathrm{~min}$ and afterward incubated with fluorophore-conjugated anti-mouse antibodies at recommended dilutions for 20 min at $4^{\circ} \mathrm{C}$. Dead cells were excluded using 7-AAD (BD Biosciences) or Fixable Viability Dye eFluor 450 (eBiosciences). During FACS acquisition, doublets were excluded. FACS antibodies used can be found in Table 1. Samples were acquired using a Symphony (BD Biosciences) and analyzed with FlowJo software (version 4.6.2, Treestar). For cell sorting, a BD Aria III (BD Biosciences) was used.

\begin{tabular}{|c|c|c|c|c|}
\hline Anti & Conjugate & Company & Cat. No. & Clone \\
\hline CD45 & APC-eFluor 780 & eBioscience & $47-0451-82$ & $30-F 11$ \\
\hline CD45 & BV510 & Biolegend & 103138 & $30-F 11$ \\
\hline CD45 & FITC & BD Pharmingen & 553772 & 104 \\
\hline CD11b & PE-Cy7 & BD Pharmingen & 552850 & M1/70 \\
\hline Ly6C & BV421 & BD Pharmingen & 562727 & AL-21 \\
\hline Ly6C & PE & BD Pharmingen & 560592 & AL-21 \\
\hline CD64a and b & BV711 & Biolegend & 139311 & X54-5/7.1 \\
\hline CD64a and b & BV421 & Biolegend & 139309 & X54-5/7.1 \\
\hline CD206 & Alexa Fluor 647 & BioLegend & 141712 & C068C2 \\
\hline CCR2 & BUV395 & BD Pharmingen & 747972 & 475301 \\
\hline Ly6G & BUV563 & BD Pharmingen & 612921 & IA8 \\
\hline Ly6G & APC & BD Pharmingen & 560599 & IA8 \\
\hline MHCII (I-A/I-E) & APC-eFluor 780 & eBioscience & $47-5321-82$ & M5/114.15.2 \\
\hline
\end{tabular}

Table 1: FACS antibodies

Muscularis ganglia isolation from adult mice. The small intestine was flushed with cold bicarbonate/ $\mathrm{CO}_{2}$ KREBS buffer. Thereafter, the myenteric plexus was collected by removing the mucosa and submucosa as previously described ${ }^{3}$. The extracted tissue was subsequently 
bioRxiv preprint doi: https:/doi.org/10.1101/2021.06.10.447700; this version posted June 10, 2021. The copyright holder for this preprint (which was not certified by peer review) is the author/funder, who has granted bioRxiv a license to display the preprint in perpetuity. It is made available under aCC-BY-NC-ND 4.0 International license.

placed in GentleMACS ${ }^{\mathrm{TM}}$ tubes (Miltenyi Biotec, Germany) with $5 \mathrm{~mL}$ of pre-warmed dissociation medium DMEM/F12 (Lonza, Belgium) supplemented with 10\% FBS (Biowest, USA), 100U/mL Penicillin/Streptomycin, 2mM L-glutamine (Lonza, Belgium), 45mg/mL NaHCO3, $0.01 \mathrm{mg} / \mathrm{mL}$ Gentamicin and $0.25 \mu \mathrm{g} / \mathrm{mL}$ Amphotericin B (Thermo Fisher).

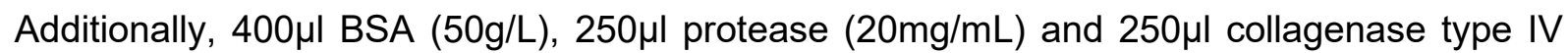
$(20 \mathrm{mg} / \mathrm{mL})$ (Sigma-Aldrich, Belgium) were added for enzymatic dissociation of tissue. The GentleMACs $^{\mathrm{TM}}$ tube was then placed into the GentleMACS ${ }^{\mathrm{TM}}$ Dissociator (Miltenyi Biotec, Germany) for mechanical dissociation for $2 \mathrm{~min}$ at room temperature. The tube was subsequently placed in a water bath at $37^{\circ} \mathrm{C}$ for $13 \mathrm{~min}$ with shaking. Subsequently, a second mechanical dissociation was performed, followed by stopping the enzymatic dissociation by addition of cold KREBS buffer. Samples were spun down at $407 \times \mathrm{g}$ at $4^{\circ} \mathrm{C}$ and re-suspended in dissociation medium without enzymes, plated in a petri dish and placed under an inverted binocular microscope, where the ganglia were picked up with a pipette tip and were lysed with RLT buffer for assessment of RNA expression levels.

Neurosphere-derived embryonic enteric glial cell culture. Neurosphere-derived EGCs were obtained as previously described ${ }^{4}$. Briefly, total intestines from E14.5 C57BL/6J mice were digested with collagenase $D(0.5 \mathrm{mg} / \mathrm{mL}$; Roche $)$ and DNase I $(0.1 \mathrm{mg} / \mathrm{mL}$; Roche $)$ in DMEM/F-12, GlutaMAX, supplemented with 1\% HEPES, streptomycin/penicillin and $0.1 \% \beta-$ mercaptoethanol (Gibco) for approximately $30 \mathrm{~min}$ at $37^{\circ} \mathrm{C}$ under gentle agitation. Cells were cultured for 1 week in a $\mathrm{CO}_{2}$ incubator at $37^{\circ} \mathrm{C}$ in DMEM/F-12, GlutaMAX, streptomycin and penicillin and $0.1 \% \beta$-mercaptoethanol (Gibco) supplemented with B27 (Gibco), $40 \mathrm{ng} / \mathrm{mL}$ EGF (Gibco) and 20 ng/mL FGF (Gibco). After 1 week of culture, neurospheres were treated with 0.05\% trypsin (Gibco), transferred into PDL (Sigma-Aldrich) coated plates and differentiated in DMEM supplemented with 10\% FBS, 1\% HEPES, glutamine, streptomycin and penicillin and $0.1 \% \beta$-mercaptoethanol (Gibco) until confluence for 5 days to obtain EGC supernatant.

RNA sequencing of neurosphere-derived EGC. RNA was isolated using RNeasy Micro Kit according to the manufacturer's instructions. A cDNA indexed library was prepared using the 
bioRxiv preprint doi: https:/doi.org/10.1101/2021.06.10.447700; this version posted June 10, 2021. The copyright holder for this preprint (which was not certified by peer review) is the author/funder, who has granted bioRxiv a license to display the preprint in perpetuity. It is made available under aCC-BY-NC-ND 4.0 International license.

Illumina TruSeq RNA library Kit and sequencing was performed on the Illumina NextSeq500 platform at the Nucleomics core (VIB, Leuven). The reads were preprocessed by trimming for quality and to remove adapters (cutadapt 1.15 and FastX 0.0 .14 ) followed by filtering for quality (FastX 0.0.14 and ShortRead 1.40.0) and removal of contaminants (bowtie 2.3.3.1). The reads were then mapped against the reference genome GRCm3882 using STAR (2.5.2b). Further filtering, sorting and indexing was done using samtools 1.5 and counts file was prepared and differential expression analysis was performed using EdgeR.

Monocyte isolation. Mouse BM monocytes were isolated from WT mice. Briefly, the tibia and femur of mice were dissected. BM cells were flushed with DMEM high glucose (Lonza) supplemented with $10 \%$ FBS. After cells were collected and counted, monocytes were isolated with the EasySep ${ }^{\mathrm{TM}}$ Mouse Monocyte Isolation Kit (Stem Cell Technologies, Vancouver, Canada) according to the manufacturer's instructions. Next, $10^{5}$ monocytes were stimulated for 24-48h with EGC supernatant, CSF-1 (50 ng/mL; PeproTech) and/or anti-CSF1r ( $5 \mu \mathrm{g} / \mathrm{mL}$; BE0213; BioXCell) at $37^{\circ} \mathrm{C}$. Cells were stimulated with LPS (100 ng/ml; Sigma-Aldrich) 6 hours prior to the end of the experiment. Monocytes were analyzed by flow cytometry or lysed with RLT buffer.

EGC proliferation assay. After 1 week of culture, enteric neurospheres were collected and dissociated to generate a single-cell suspension by using the NeuroCult ${ }^{\mathrm{TM}}$ Chemical Dissociation Kit (Mouse) (Stem Cell Technologies, CatN05707). Next, cells were filtered through a $70 \mu \mathrm{m}$ cell strainer and counted using a burker chamber. EGCs were transferred into poly-D-Lysine (Gibco, CatN A3890401) coated 96-well plates at a concentration of 5000 cells per well and $100 \mu \mathrm{l}$ of conditioned medium was added to each well. To obtain conditioned medium from myeloid cells, Ly6C ${ }^{\text {hi }}$ monocytes from 24 h post-injury and Ly6C- $\mathrm{MHCII}^{\text {hi }} \mathrm{M} \varphi s$ from $72 \mathrm{~h}$ post-injury were sorted from the muscularis and cultured at a concentration of 50.000 cells/well per $400 \mu \mathrm{l}$ medium with $0.5 \%$ FBS during $24 \mathrm{~h}$. After 5 days of culture in (un)conditioned media, the proliferation of the EGCs was measured by using the Cell Counting Kit-8 (Tebu-bio, CatN ${ }^{\circ} \mathrm{CK04-05).} \mathrm{After} 2$ hours of incubation with the CCK-8 solution, the 
absorbance was measured at $450 \mathrm{~nm}$ and $600 \mathrm{~nm}$ (background signal) using a microplate reader. Data were expressed as induction with respect to EGCs cultured with unconditioned medium.

RNA extraction and gene expression of ganglia and myeloid cells. Picked ganglia from the small intestine and monocytes/macropahges were lysed in RLT buffer and stored at $-80^{\circ} \mathrm{C}$. RNA extraction was performed using RNeasy Mini Kit for tissue and high cell numbers (Qiagen) or RNeasy Micro Kit for low cell numbers following manufacturer's instructions. Total RNA was transcribed into cDNA by the High-Capacity cDNA Reverse Transcription Kit (Thermo Fisher) according to manufacturer's instructions. Quantitative real-time transcription polymerase chain reactions (RT-PCR) were performed with the LightCycler 480 SYBR Green I Master (Roche) on the Light Cycler 480 (Roche). Results were quantified using the 2- $\Delta \Delta \mathrm{CT}$ method $^{5}$. Expression levels of the genes of interest were normalized to the expression levels of the reference gene Rpl32. Results are expressed as mean values and primer sequences used are listed in Table 2.

\begin{tabular}{|l|l|l|}
\hline & Forward primer & Reverse primer \\
\hline Rpl32 & AAGCGAACTGGCGGAAAC & TAACCGATGTTGGGCATCAG \\
\hline Arg1 & CAGAAGAATGGAAGAGTCAG & CAGATATGCAGGGAGTCACC \\
\hline Ccl2 & CAGGTGTCCCAAAGAAGCTGTA & CATTTGGTTCCGATCCAGG \\
\hline Csf1 & ATGAGCAGGAGTATTGCCAAGG & TCCATTCCCAATCATGTGGCTA \\
\hline$\| 10$ & CCAAGCCTTATCGGAAATGA & TCACTCTTCACCTGCTCCAC \\
\hline$\| 16$ & CCATAGCTACCTGGAGTACATG & TGGAAATTGGGGTAGGAAGGAC \\
\hline$\| 12$ & CCTGCTGAAGACCACAGATG & AGCTCCCTCTTGTTGTGGAA \\
\hline Mrc1 & CTCTGTTCAGCTATTGGACGC & TGGCACTCCCAAACATAATTTGA \\
\hline Nos2 & GCTTCTGGTCGATGTCATGAG & TCCACCAGGAGATGTTGAAC \\
\hline
\end{tabular}

Table 2: List of RT-PCR primers

Isolation and sequencing of ribosome-associated mRNA from EGCs. To induce gene recombination of $\mathrm{Rp} 22^{\mathrm{HA}}$ in PLP $1^{\mathrm{CreERT} 2} \mathrm{Rpl} 22^{\mathrm{HA}}$ transgenic mice at $10-12$ weeks of age, mice were injected twice intraperitoneally with $100 \mu \mathrm{l}$ of $15 \mathrm{mg} / \mathrm{mL}$ tamoxifen (Sigma-Aldrich) dissolved in Miglyol 812 (Caesar \& Loretz, Hilden, Germany). All animals were sacrificed 3-4 weeks after the first injection. The whole small intestine of each mouse was peeled by removing the mucosa and submucosa and samples were flash-frozen in liquid nitrogen and 
bioRxiv preprint doi: https:/doi.org/10.1101/2021.06.10.447700; this version posted June 10, 2021. The copyright holder for this preprint (which was not certified by peer review) is the author/funder, who has granted bioRxiv a license to display the preprint in perpetuity. It is made available under aCC-BY-NC-ND 4.0 International license.

stored at $-80^{\circ} \mathrm{C}$ until further processing. Samples were immunoprecipitated at the Weizman Instiute (Israel) according to the published protocol ${ }^{6,7}$. In brief, samples were homogenized in $4 \mathrm{~mL}$ cold homogenization buffer $(50 \mathrm{mM}$ Tris, $\mathrm{pH} 7.4,100 \mathrm{mM} \mathrm{KCl}, 12 \mathrm{mM} \mathrm{MgCl} 2,1 \% \mathrm{NP}$ 40, $1 \mathrm{mM}$ DTT, 1:100 protease inhibitor (Sigma-Aldrich), $200 \mathrm{U} / \mathrm{mL}$ RNasin (Promega) and 0.1 $\mathrm{mg} / \mathrm{mL}$ cycloheximide (Sigma-Aldrich)) with a Dounce homogenizer (Sigma-Aldrich) until the suspension was homogeneous. To remove cell debris, $2 \mathrm{~mL}$ of the homogenate was transferred to a microcentrifuge tube and centrifuged at $10,000 \mathrm{~g}$ at $4^{\circ} \mathrm{C}$ for $10 \mathrm{~min}$. Supernatants were transferred and split, and $8 \mu \mathrm{L}(10 \mu \mathrm{g})$ of anti-HA antibody (H9658, SigmaAldrich) or $20 \mu \mathrm{L}(10 \mu \mathrm{g})$ of mouse monoclonal IgG1 antibody (Sigma-Aldrich, Cat\# M5284) was added to the supernatant, followed by $4 \mathrm{~h}$ of incubation with slow rotation at $4^{\circ} \mathrm{C}$. Meanwhile, Dynabeads Protein G (Thermo Fisher), were equilibrated to homogenization buffer by washing three times. At the end of $4 \mathrm{~h}$ of incubation with antibody, beads were added to each sample, followed by incubation overnight at $4^{\circ} \mathrm{C}$. Next, samples were washed three times with high-salt buffer (50 mM Tris, $300 \mathrm{mM} \mathrm{KCl,} 12 \mathrm{mM} \mathrm{MgCl}$, 1\% NP-40, 1 mM DTT, 1:200 protease inhibitor, $100 \mathrm{U} / \mathrm{mL}$ RNasin and $0.1 \mathrm{mg} / \mathrm{mL}$ cycloheximide). At the end of the washes, beads were magnetized and excess buffer was removed, $150 \mu$ lysis buffer was added to the beads and RNA was extracted with Dynabeads mRNA Direct purification kit (Thermo Fisher) according to manufacturer's instructions. RNA was eluted in $6 \mu \mathrm{l} \mathrm{H}_{2} \mathrm{O}$ and used for RNA-seq.

\section{RNAseq library preparation and analysis of immunoprecipitated samples.} Immunoprecipitated samples were processed and analyzed according to published protocols ${ }^{6}$ 7. In brief, mRNA was captured with Dynabeads oligo(dT) (Life Technologies) according to manufacturer's guidelines. A bulk variation of MARSseq ${ }^{8}$ was used to prepare libraries for RNA-seq. RNA was reversed transcribed with MARSseq barcoded RT primer in a $10 \mathrm{~mL}$ volume with the Affinity Script kit (Agilent). Reverse transcription was analyzed by qRT-PCR and samples with a similar CT were pooled (up to eight samples per pool). Each pool was treated with Exonuclease I (NEB) for $30 \mathrm{~min}$ at $37^{\circ} \mathrm{C}$ and subsequently cleaned by $1.2 \mathrm{x}$ volumes of SPRI beads (Beckman Coulter). Subsequently, the cDNA was converted to double- 
stranded DNA with a second strand synthesis kit (NEB) in a $20 \mathrm{~mL}$ reaction, incubating for $2 \mathrm{~h}$ at $16^{\circ} \mathrm{C}$. The product was purified with $1.4 \times$ volumes of SPRI beads, eluted in $8 \mathrm{~mL}$ and in vitro transcribed (with the beads) at $37^{\circ} \mathrm{C}$ overnight for linear amplification using the $\mathrm{T} 7 \mathrm{High}$ Yield RNA polymerase in vitro transcription kit (NEB). Following in vitro transcription, the DNA template was removed with Turbo DNase I (Ambion) for $15 \mathrm{~min}$ at $37^{\circ} \mathrm{C}$ and the amplified RNA (aRNA) was purified with 1.2 volumes of SPRI beads. The aRNA was fragmented by incubating in $\mathrm{Zn}^{2+} \mathrm{RNA}$ fragmentation reagents (Ambion) for $3 \mathrm{~min}$ at $70^{\circ} \mathrm{C}$ and purified with $2 \mathrm{x}$ volumes of SPRI beads. The aRNA was ligated to the MARS-seq ligation adaptor with T4 RNA Ligase I (NEB). The reaction was incubated for $2 \mathrm{~h}$ at $22^{\circ} \mathrm{C}$. After $1.5 \times$ SPRI cleanup, the ligated product was reverse transcribed using Affinity Script RT enzyme (Agilent) and a primer complementary to the ligated adaptor. The reaction was incubated for $2 \min$ at $42^{\circ} \mathrm{C}$, for 45 min at $50^{\circ} \mathrm{C}$, and for $5 \mathrm{~min}$ at $85^{\circ} \mathrm{C}$. The cDNA was purified with $1.5 \mathrm{x}$ volumes of SPRI beads. The library was completed and amplified through a nested PCR reaction with $0.5 \mathrm{mM}$ of P5_Rd1 and P7_Rd2 primers and PCR ready mix (Kappa Biosystems). The amplified pooled library was purified with $0.7 \times$ volumes of SPRI beads to remove primer leftovers. Library concentration was measured with a Qubit fluorometer (Life Technologies) and mean molecule size was determined with a 2200 TapeStation instrument. RNaseq libraries were sequenced using the Illumina NextSeq 2000.

Data analysis was performed by using the UTAP transcriptome analysis pipeline ${ }^{9}$. Raw reads were trimmed using cutadapt with the parameters: -a AGATCGgAAGAGCACACGTCTGAACTCCAGTCAC -a "A-times 2 -u 3 -u -3 -q 20 -m 25). Reads were mapped to the genome (mm10, Gencode annotation version 10.0) using STAR (v2.4.2a) with the parameters -alignEndsType EndToEnd, -outFilterMismatchNoverLmax 0.05, -twopassMode Basic, -alignSoftClipAtReferenceEnds No. The pipeline quantifies the 3' of Gencode annotated genes. UMI counting was done after marking duplicates (in-house script) using HTSeq-count in union mode. Only reads with unique mapping were considered for further analysis, and genes having minimum 10 reads in at least one sample were 
considered. Gene expression levels were calculated and normalized using DESeq2 (1.26.0) with default parameters except alpha $=0.05^{10}$.

Single cell RNA sequencing - Library preparation and sequencing. Single cell RNA sequencing libraries were prepared using the 10X Genomics platform according to manufacturer's instructions (Single cell 3' solution) and sequencing was performed on Illumina NextSeq500 (Illumina). Cell Ranger software (v3.0.2; 10X Genomics) was used to demultiplex Illumina BCL files to FASTQ files (cellranger mkfastq) for alignment to mouse GRCm38/mm10 genome, filtering, UMI counting, and to produce gene-barcode matrices. Library preparation, sequencing and sample demultiplexing were performed at the Genomics Platform of the GIGA Institute (Liège University, Belgium).

Single-cell RNA sequencing Clustering and Dimensionality reduction. The filtered count matrices obtained after pre-processing with Cellranger were concatenated to obtain a combined raw count matrix which was then analyzed using the Seurat R package (3.1.3). Cells with less than 200 genes, cells with more than $10 \%$ mitochondrial genes and genes with expression in less than 3 cells were discarded from the analysis. SCTransform function was used for normalization and scaling. A regression of the percentage of mitochondrial genes was performed during the SCTransform step. Next, principal component analysis was used to reduce the dimension of the data before UMAP construction and clustering. The cells annotated as monocytes and $M \varphi s$ were then employed to subset original concatenated counts matrix. The subset matrix was then subjected to the same process of normalization, scaling (SCTransform), principal component analysis, UMAP projection and clustering. The MHC II signature score was calculated using 'AUCell' R package as the 'area under the curve' with the following genes - H2-Ab1, H2-Aa, H2-Eb1, H2-Eb2, H2-DMa, H2-DMb1, H2-DMb2. During the re-clustering of monocytes and M $\varphi$ s from WT and CCR2 $2^{--}$mice, 67 cells appeared to be granulocytes/DCs (based on Cxcr2 and Cd209a expression) and were not included in the reclustering analysis of mono/M $\varphi s$. Analysis plots were generated using the R packages ggplot (3.2.1), pheatmap (1.0.12) and EnhancedVolcano (1.4.0). Markers for different clusters were 
determined using a Wilcoxon rank test with FindMarkers and FindAllMarkers functions in Seurat. Non-default parameters used at each step during clustering or re-clustering with Seurat are given in Table 3.

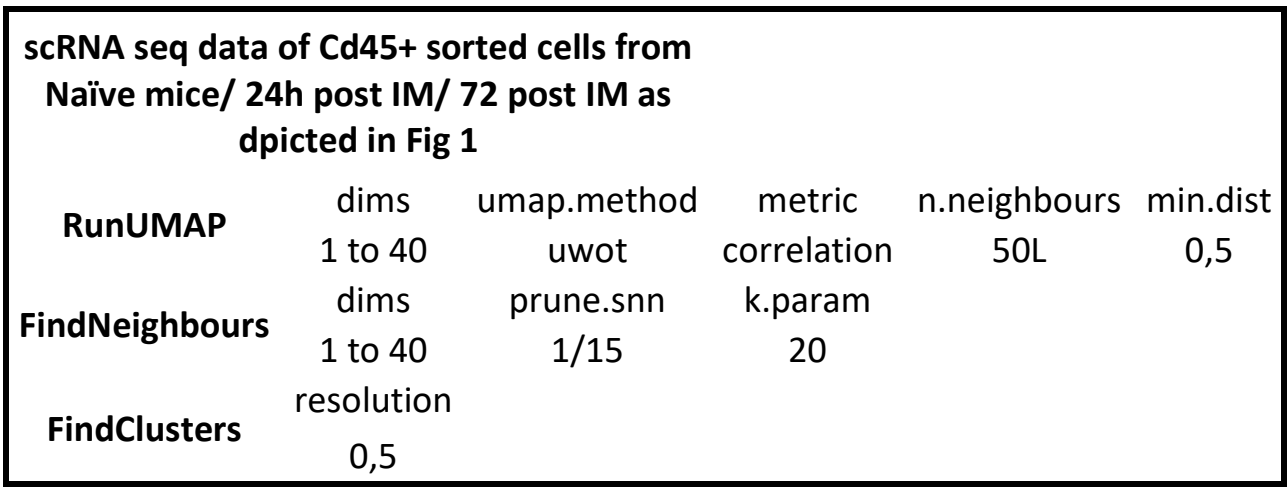

\begin{tabular}{|c|c|c|c|c|c|}
\hline \multicolumn{2}{|c|}{$\begin{array}{l}\text { scRNA seq data of Cd45+ sorted cells from } \\
\text { WT/CCR2 KO mice } 24 \mathrm{~h} \text { post IM/ } 72 \text { post }\end{array}$} & $\begin{array}{l}\text { rted cells from } \\
\text { t IM/ } 72 \text { post }\end{array}$ & & & \\
\hline \multirow{2}{*}{ RunUMAP } & dims & umap.method & metric & n. neighbours & min.dist \\
\hline & $\begin{array}{l}1 \text { to } 40 \\
\operatorname{dims}\end{array}$ & $\begin{array}{l}\text { uwot } \\
\text { prune.snn }\end{array}$ & $\begin{array}{l}\text { correlation } \\
\text { k.param }\end{array}$ & $50 \mathrm{~L}$ & 0,5 \\
\hline FindNeighbours & $\begin{array}{l}1 \text { to } 40 \\
\text { resolution }\end{array}$ & $1 / 15$ & 20 & & \\
\hline rinaciusters & 0,5 & & & & \\
\hline
\end{tabular}

Reclustering of Monocytes and Macrophages cells from Fig1 as depicted in Fig 2

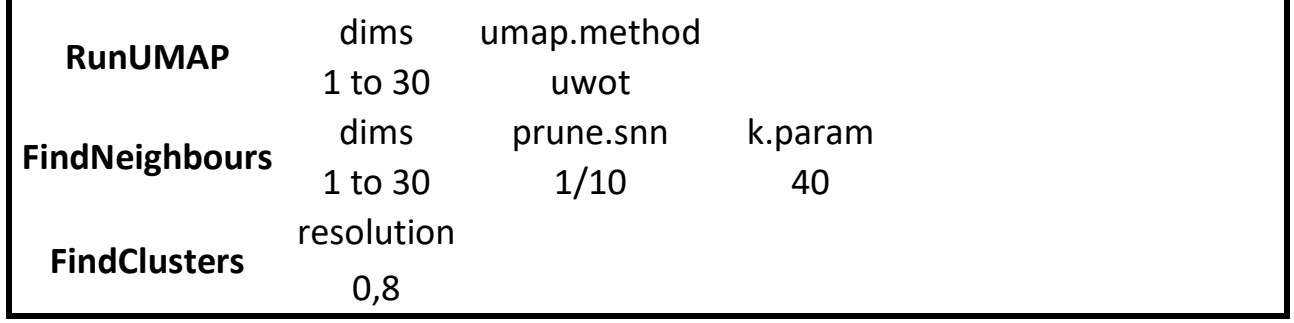

\begin{tabular}{|c|c|c|c|}
\hline $\begin{array}{r}\text { Reclusteri } \\
\text { Macrophages ce } \\
\text { data as }\end{array}$ & $\begin{array}{l}\text { ig of Mono } \\
\text { Is from WT } \\
\text { depicted ir }\end{array}$ & $\begin{array}{l}\text { ytes and } \\
\text { /CCR2 KO mice } \\
\text { Fig } 4\end{array}$ & \\
\hline RunUMAP & $\begin{array}{c}\operatorname{dims} \\
1 \text { to } 30\end{array}$ & $\begin{array}{c}\text { umap.method } \\
\text { uwot }\end{array}$ & \\
\hline FindNeighbours & dims & prune.snn & k.param \\
\hline rinaiveignioours & 1 to 30 & $1 / 10$ & 40 \\
\hline FindClusters & resolution & & \\
\hline - & 0,7 & & \\
\hline
\end{tabular}

Supplementary Table 3: Non-default parameters Seurat. 
Trajectory inference using Monocle-2. Monocle-2 was used with the raw count matrix of all monocytes and macrophages from WT data (depicted in Figure 2A). Cells were clustered with 'densityPeak' method (rho_threshold $=40$, delta_threshold $=10$ ). Top 3000 genes by q-value determined using differentialGeneTest() function were used as 'ordering genes'. Finally, DDRTree dimensionality reduction was performed and cells were ordered using orderCells() function.

Inferring cell-cell communication using NicheNet. We used NicheNet (nichenetr R package; version - 0.1.0) to study the interactions between EGCs and infiltrating monocytes after muscularis inflammation. To identify EGC derived ligands potentially inducing differentiation of $\mathrm{Ly}_{6 \mathrm{c}^{+}}$monocytes into $\mathrm{Ccr}^{+}$inte $\mathrm{M} \varphi \mathrm{s}$, RiboTag bulk sequencing data from PLP1 ${ }^{\text {CreERT2 }}{ }^{\mathrm{Rp}} 22^{\mathrm{HA}}$ mice in homeostasis and $3 \mathrm{~h}$ after the induction of muscularis inflammation were used. Ligands were identified after filtering for genes upregulated 3h post-injury in PLP1+ EGCs with respect to homeostasis (adjusted p value $<0.05$ ) and enriched in the HA sample with respect to the IgG control. Genes differentially expressed between $\mathrm{Ccr} 2^{+}$int $M \varphi s$ and Ly6c $c^{+}$monocytes (adjusted $p$ value $<0.05$ ) were considered as the gene set of interest. Genes expressed in at least $10 \%$ of the Ly6c+ monocyte cluster excluding genes in the gene set of interest were considered as the background expressed genes in Ly6 $\mathrm{c}^{+}$monocytes.

Single-cell regulatory network inference and clustering (SCENIC). SCENIC analysis was run as described by Aibar et al. (0.1.5) using the 10-thousand motifs annotation database and 500bp annotation database using pySCENIC (version 0.10 .0$)^{11}$ on monocytes and M $\varphi s$ (2249 cells). The input matrix was the UMI 'corrected', log normalized expression matrix. Databases of CisTarget - (mm10_refseq-r80_10kb_up_and_down_tss.mc9nr.feather, mm10_refseqr80_500bp_up_and_100bp_down_tss.mc9nr.feather), and the transcription factor motif annotation database (motifs-v9-nr.mgi-m0.001-o0.0.tbl) from resources.aertslab.org/cistarget/, and the list of human transcription factors (mm_mgi_tfs.txt) from github.com/aertslab/pySCENIC/tree/master/resources were employed for the analysis. Significance of regulons for each cluster was assessed by a Wilcoxon test on AUC values. 
Functional analysis of gene sets. Differentially upregulated genes in each cluster compared to the others were used with enrichGO function from the clusterprofiler R package (version 3.14.3) $)^{12}$ to perform gene set analysis against the Gene Ontology annotation from org.Mm.eg.db R package (version 3.10.0). Data visualization was prepared using ggplot2 $\mathrm{R}$ package.

Reference-based annotation using SingleR. SingleR was used for reference-based annotation ${ }^{13}$. Data from Immgen was employed as reference to guide the annotation of CD45 immune cells sorted from the muscularis of WT mice ${ }^{14}$. For the annotation of the mono/M $\varphi$ subsets from WT and CCR2--/ mice, the manually curated annotations from the monocyte/M $\varphi$ subpopulations of Fig. 2 was used as reference.

Gene Set Enrichment Analysis. Gene Set Enrichment Analysis (GSEA) was performed using the GSEA software from the Broad Institute (version 4.0.2). Normalized counts of bulk RNA sequencing from $\mathrm{PLP} 1^{+}$cells from the muscularis of PLP1 ${ }^{\text {CreERT2 }} \mathrm{Rpl} 22^{\mathrm{HA}}$ mice at homeostasis and $3 \mathrm{~h}$ after the induction of muscularis inflammation were used. Only genes that were significantly upregulated in the HA-tagged sample over the IgG control (adjusted $p$ value cut off $<0.05$ and $\log 2$ (fold change) $>0.05$ ) were used for the analysis. Extra data visualization was prepared using ggplot2 $\mathrm{R}$ package. 
bioRxiv preprint doi: https://doi.org/10.1101/2021.06.10.447700; this version posted June 10, 2021. The copyright holder for this preprint (which was not certified by peer review) is the author/funder, who has granted bioRxiv a license to display the preprint in perpetuity. It is made available under aCC-BY-NC-ND 4.0 International license.

\section{Supplementary figures:}

A
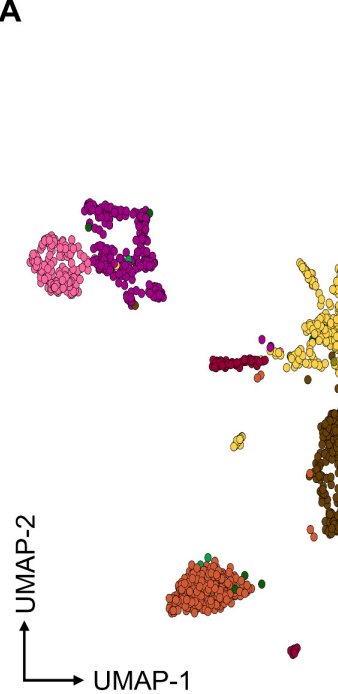

UMAP-1

$\begin{array}{llllll}0 & \text { Monocytes } & \text { Ly6c2 } & 6 & \text { Neutrophils_2 } & \text { S100a8 } \\ 1 & M \varphi \_1 & \text { CD68 } & 7 & \text { Eosinophils } & \text { Siglec-f } \\ 2 & M \varphi \_2 & \text { Ccl9 } & 8 & \text { ILCs } & \text { Thy1 } \\ \text { 3 } & M \varphi \_3 & \text { Cx3cr1 } & 9 \text { T cells } & \text { Cd3e } \\ 4 & \text { DCs } & \text { Itgax } & 10 \text { B cells_1 } & \text { Cd20 } \\ 5 & \text { Neutrophils_1 } & \text { S100a9 } & 11 \text { B cells_2 } & \text { Cd19 }\end{array}$

B

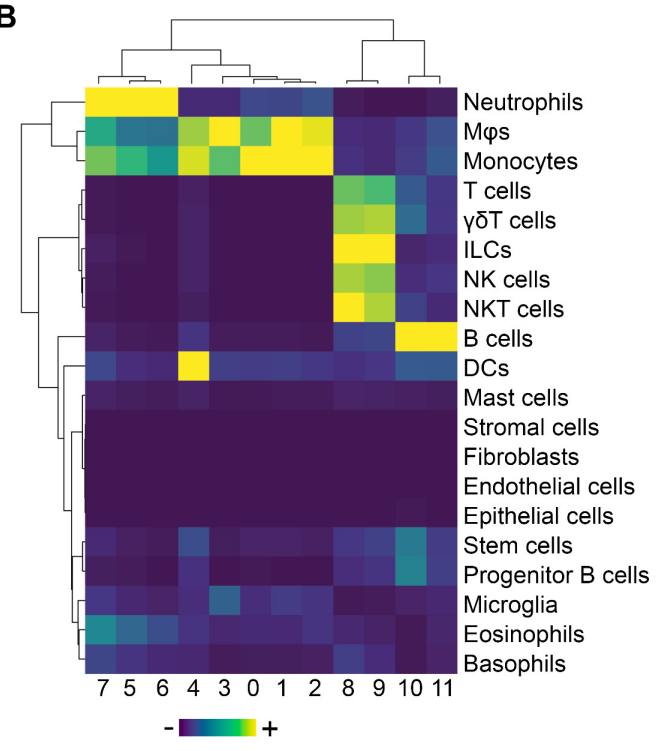

Supplementary Figure 1: SingleR annotation of $C D 45^{+}$immune cells in the healthy and inflamed muscularis. A. UMAP of sorted CD45 immune cells from the healthy muscularis, $24 \mathrm{~h}$ and $72 \mathrm{~h}$ after the induction of muscularis inflammation. Reproduction of Figure 1B. B. Automated SingleR annotation of clusters from Supplementary Fig. 1A using ImmGen as a reference database. 
bioRxiv preprint doi: https://doi.org/10.1101/2021.06.10.447700; this version posted June 10, 2021. The copyright holder for this preprint (which was not certified by peer review) is the author/funder, who has granted bioRxiv a license to display the preprint in perpetuity. It is made available under aCC-BY-NC-ND 4.0 International license.

A

A

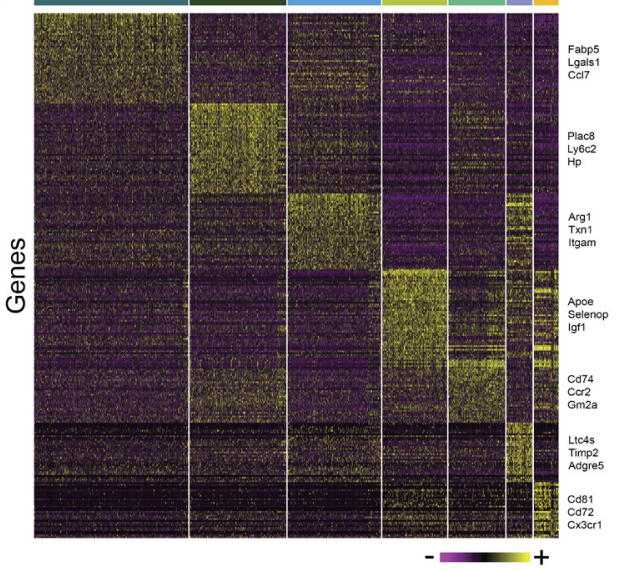

C

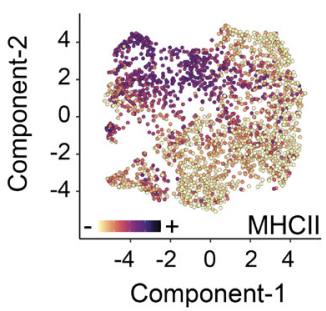

E
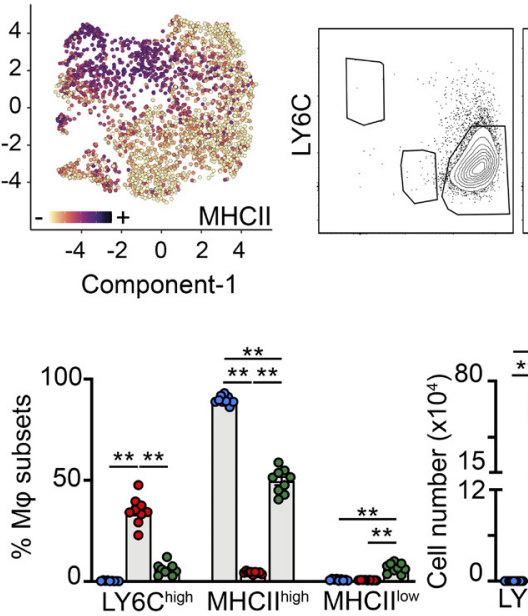

B

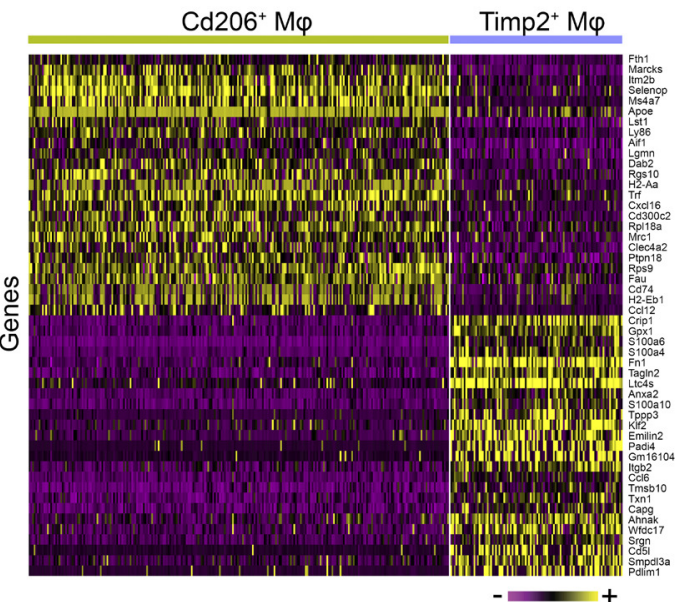

Live CD45+ CD11b+ Ly6G CD64 ${ }^{+}$
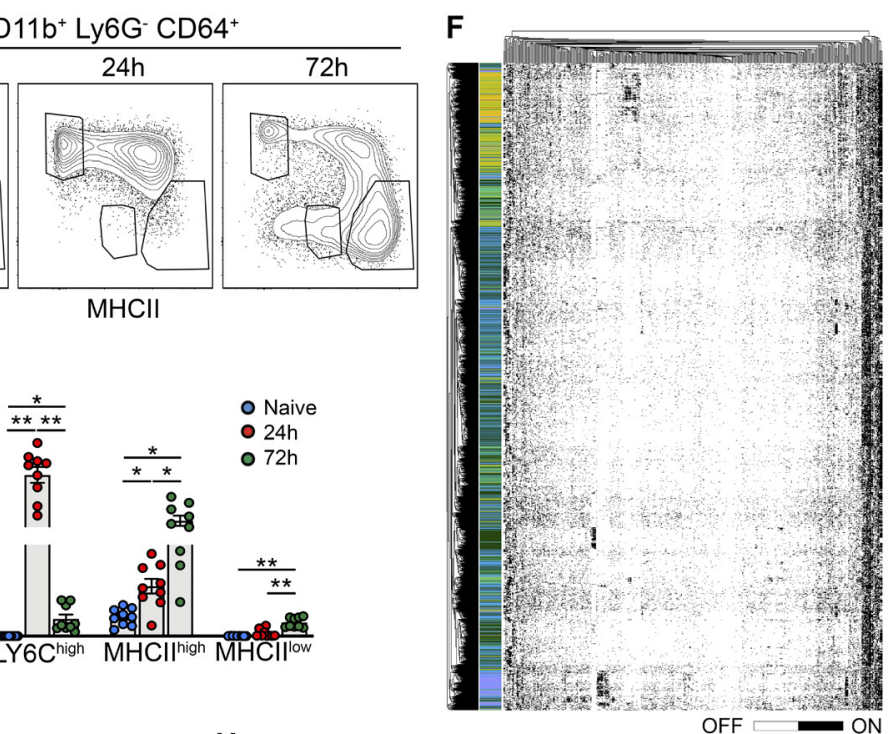

G
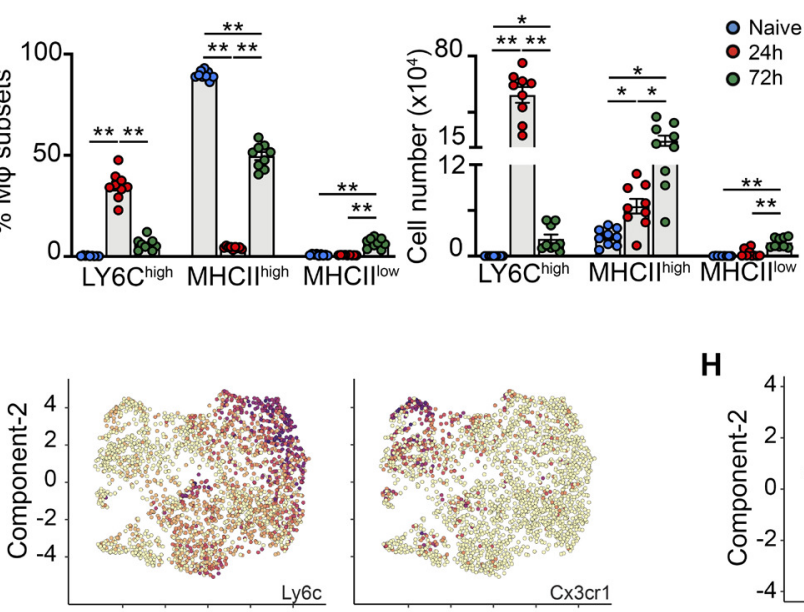

H
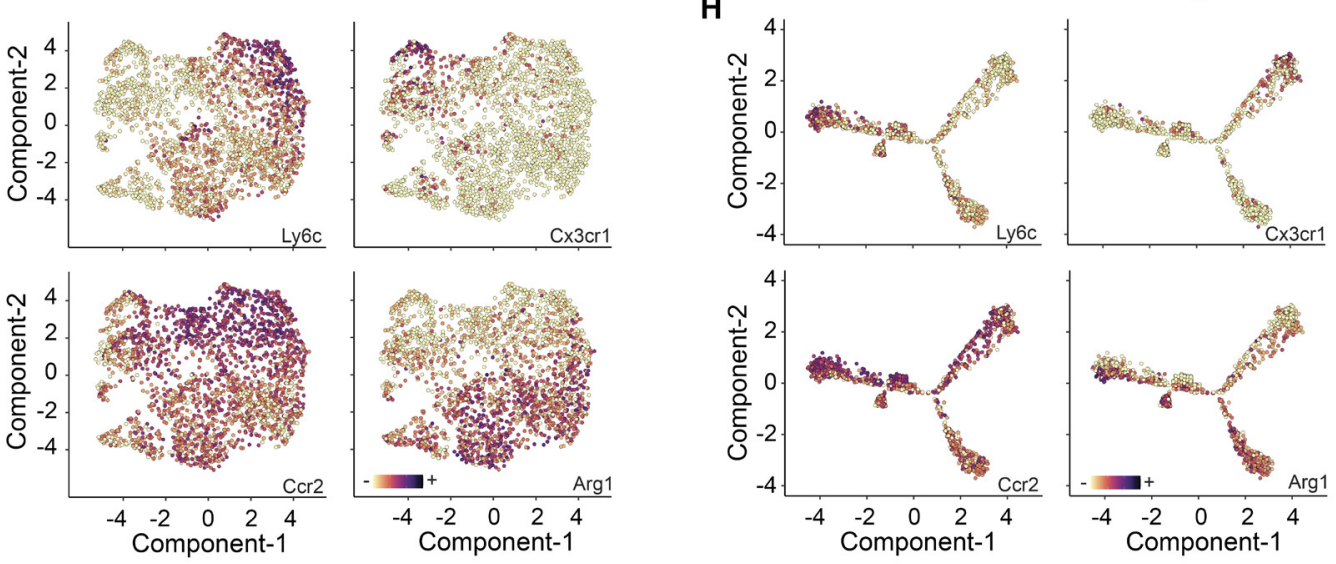

Supplementary Figure 2: Marker expression in myeloid sub-clustering. A. Heatmap of 50 most differentially expressed genes in each cluster from Fig. 2A. B. Heatmap of 25 most differentially expressed genes between $\mathrm{Cd}_{206^{+}}$and Timp2 ${ }^{+} \mathrm{M} \varphi$ s. C. UMAP depicting the expression of the MHCll gene signature. D-E. Immune cells isolated from the muscularis at homeostasis, $24 \mathrm{~h}$ and $72 \mathrm{~h}$ after muscularis inflammation were analyzed via flow cytometry. Representative contour plots showing Ly6Chi

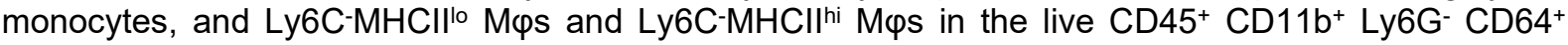

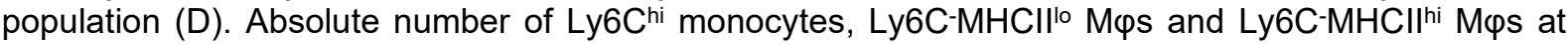
different time points after muscularis inflammation. Data are shown as mean $\pm \mathrm{SEM}$. One-way ANOVA. ${ }^{*} p<0.05 ;{ }^{* *} p<0.01$. (E). F. Hierarchically clustered heatmap showing 'binarized' regulon activity (ON/OFF indicated in Black/White) in each cell. Cells are annotated with the same colors as indicated in Figure 2A. G. Single cell gene expression of indicated markers projected onto UMAP. H. Single cell gene expression of indicated markers projected onto the Monocle trajectory. 
bioRxiv preprint doi: https://doi.org/10.1101/2021.06.10.447700; this version posted June 10, 2021. The copyright holder for this preprint (which was not certified by peer review) is the author/funder, who has granted bioRxiv a license to display the preprint in perpetuity. It is made available under aCC-BY-NC-ND 4.0 International license.

A
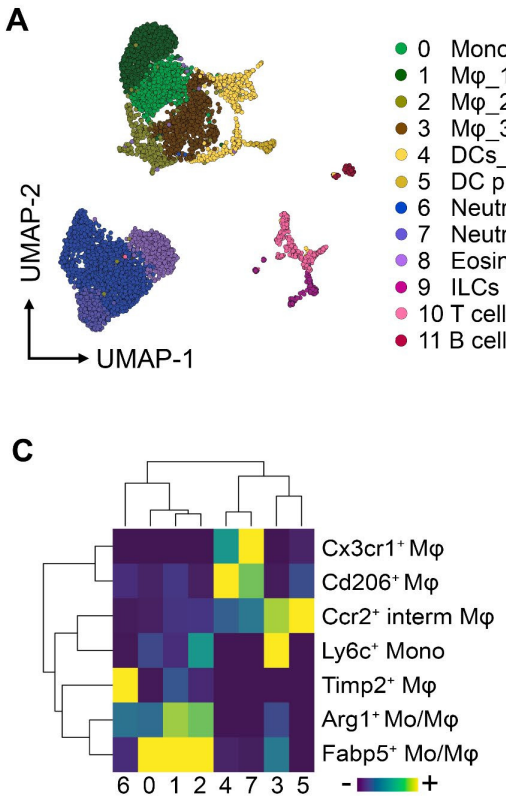

B

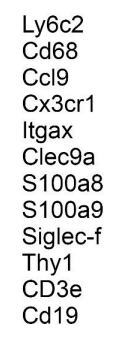

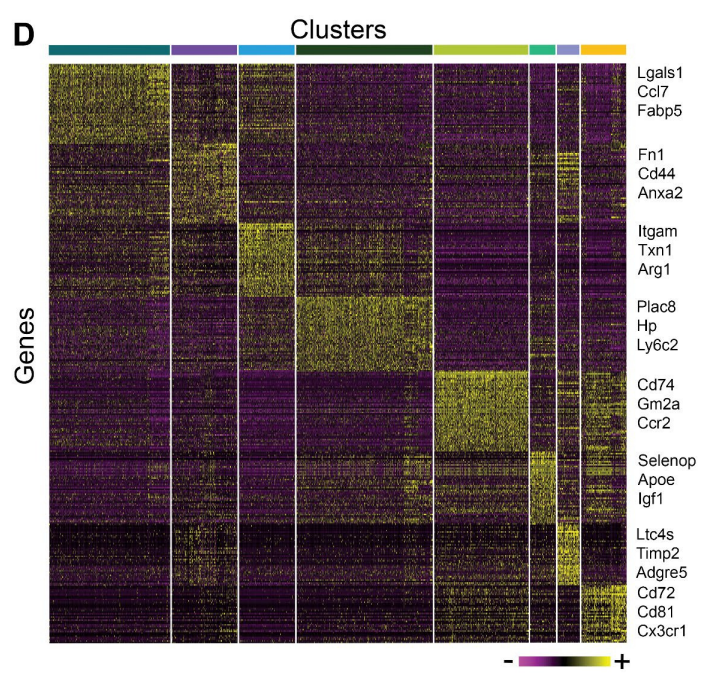

Supplementary Figure 3: Analysis of myeloid cells in CCR2 ${ }^{-1-}$ mice during muscularis inflammation. A-D. scRNAseq on sorted CD45+ immune cells from WT and CCR2-- mice $24 \mathrm{~h}$ and $72 \mathrm{~h}$ after the induction of muscularis inflammation. A. UMAP of sorted CD45 immune cells. B. UMAP of myeloid subclusters. C. Automated SingleR annotation of subclusters from Supplementary Fig. 3B based on the gene signature of subclusters from Fig. 2A. D. Heatmap of 50 most differentially expressed genes in each subcluster from Supplementary Fig. 3B. 
A

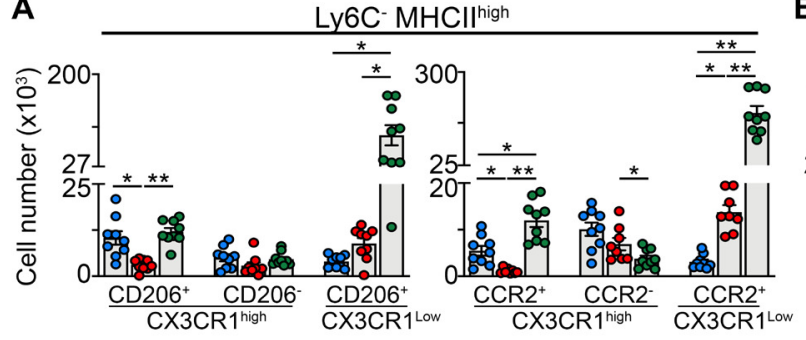

C
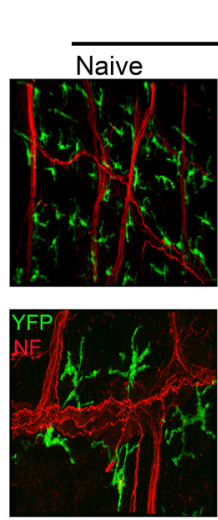

CX3Cr1 ${ }^{\text {CreERT2 }} R 26^{\text {YFP }}$
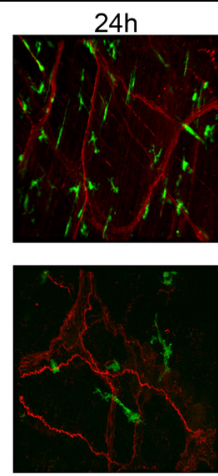

E

Live CD45+ CD11 b ${ }^{+}$Ly6G- CD64+Ly6C-MHCII ${ }^{\text {High }}$

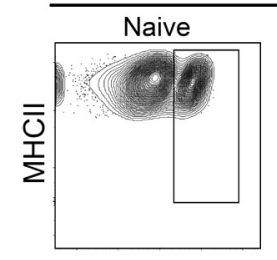

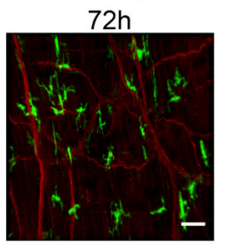
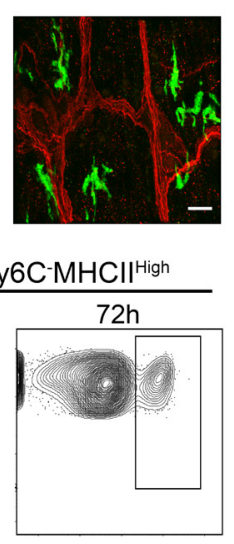

B

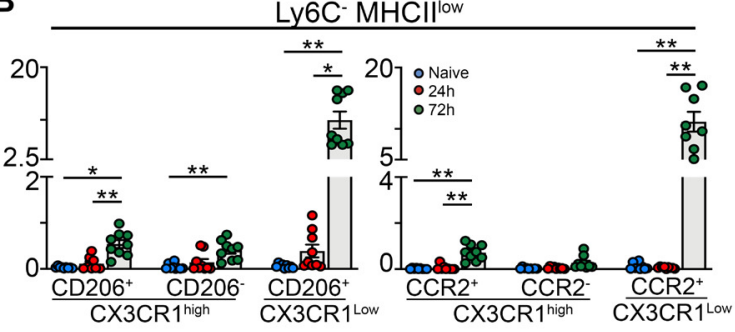

D

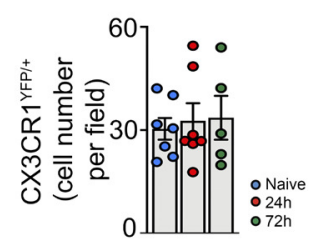

$\mathbf{F}$

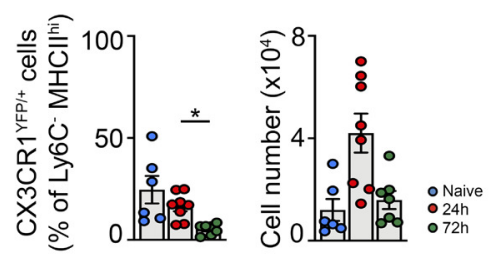

Supplementary Figure 4: Resident macrophages are not depleted upon muscularis inflammation. A-B. Analysis of absolute number of CD206 ${ }^{+}$CX3CR $1^{\text {hi }}$, CD206- CX3CR $1^{\text {hi }}$ and CD206 ${ }^{+}$

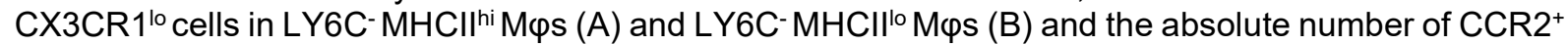
CX3CR1 $1^{\text {hi }}$, CCR2- CX3CR1 $1^{\text {hi }}$ and CCR2 ${ }^{+}$CX3CR1 $1^{\text {lo }}$ cells in the LY6C- MHCll ${ }^{\text {hi }} M \varphi s(A)$ and LY6C$\mathrm{MHCIl}{ }^{\circ} \mathrm{M} \varphi s$ (B) from Fig. 4C,F. C-F. Analysis of the number of resident $\mathrm{YFP}^{+} \mathrm{M} \varphi$ s during muscularis inflammation (naïve, 24h and 72h) using tamoxifen-injected CX3CR1 ${ }^{\text {CreERT2/+ }}$ Rosa26-LSL-YFP mice. C. Representative immunofluorescent images of muscularis whole mount preparations at different time points after muscularis inflammation, stained for YFP (green) and neurofilament (red). Scale bar $40 \mu \mathrm{m}$ (top; 25X); $15 \mu \mathrm{m}$ (bottom; 63X). D. Number of CX3CR1-YFP+ cells per field. Each dot represents the average from an individual mouse and mean \pm SEM are shown. Data are combined from 2 independent experiments. E. Contour plots showing CX3CR1-YFP expression in $\mathrm{LY} 6 \mathrm{C}^{-} \mathrm{MHCl} \mathrm{I}^{\mathrm{hi}} \mathrm{M} \varphi \mathrm{s}$ at homeostasis and $24 \mathrm{~h}$ and $72 \mathrm{~h}$ after muscularis inflammation. F. Percentage of CX3CR $1^{\mathrm{YFP} /+}$ cells in LY6C- MHCII $\mathrm{hi}^{\mathrm{hi}}$ M $\varphi s$ (left) and absolute number of cells (right) at different time points after muscularis inflammation. $A$, $\mathrm{B}, \mathrm{D}, \mathrm{F}$; one-way ANOVA. ${ }^{*} \mathrm{p}<0.05 ;{ }^{* *} \mathrm{p}<0.01$, ns $=$ not significant. 
bioRxiv preprint doi: https://doi.org/10.1101/2021.06.10.447700; this version posted June 10, 2021. The copyright holder for this preprint (which was not certified by peer review) is the author/funder, who has granted bioRxiv a license to display the preprint in perpetuity. It is made available under aCC-BY-NC-ND 4.0 International license.

A PLPCRERT2.RP/22 HA

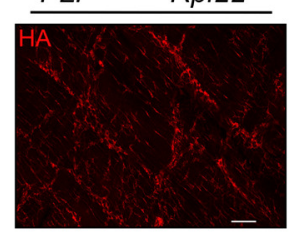

B

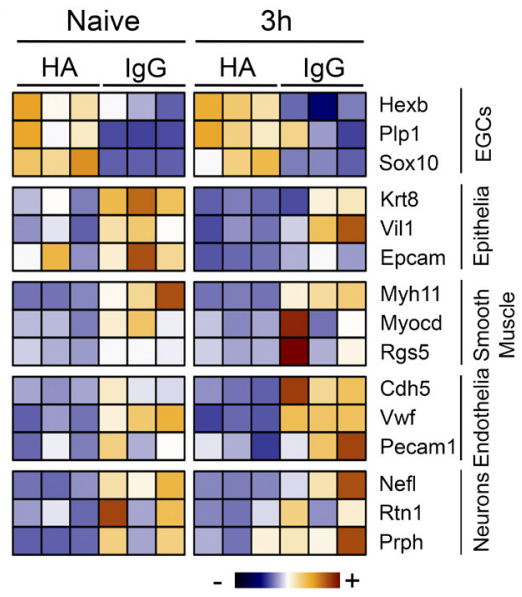

C

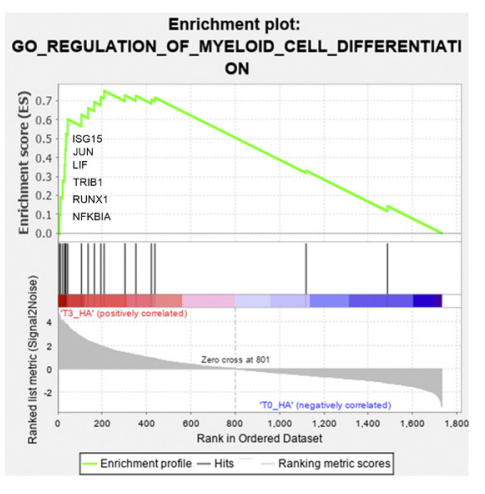

D

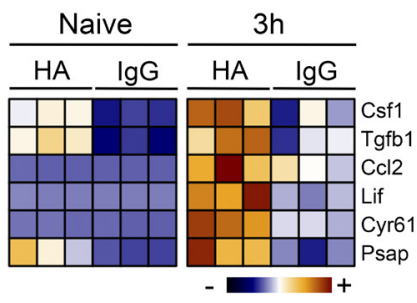

$\mathbf{F}$

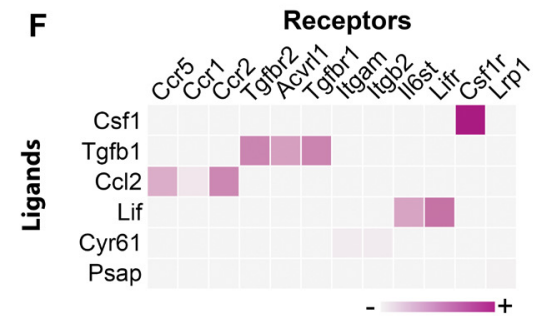

Receptors

E

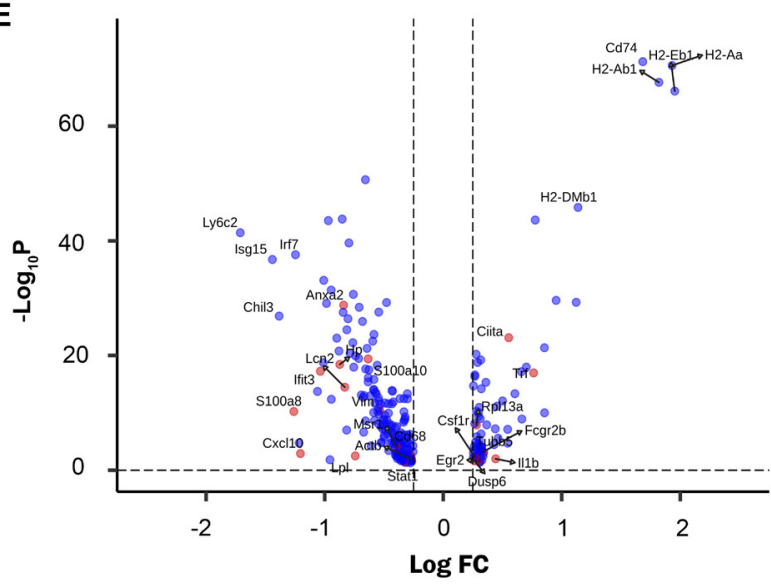

Supplementary Figure 5: Characterization of EGCs at homeostasis and during muscularis inflammation. A. Immunofluorescent image of muscularis whole mount preparation of a tamoxifeninjected PLPCreERT2/+ Rpl22 $2^{\mathrm{HA}}$ mouse stained for HA tag (red). Scale bar $30 \mu \mathrm{m}$. B. Heat map of gene expression from IgG control or immunoprecipitated muscularis from naive mice or $3 \mathrm{~h}$ after the induction of muscularis inflammation showing genes characteristics for different cell types. C. Visualization of GSEA analysis for regulation of myeloid cell differentiation. D. Heatmap of all positively correlated upstream ligands from NicheNet analysis. E. Volcano plot of differentially expressed genes between $\mathrm{Ccr} 2^{+}$int $\mathrm{M} \varphi s$ and $\mathrm{Ly}_{6} \mathrm{c}^{+}$monocytes highlighting target genes of top ligands from NicheNet in $\mathrm{Ly}_{6 \mathrm{C}^{+}}$ monocytes and $\mathrm{Ccr}^{+}$int $\mathrm{M} \varphi \mathrm{s}$. F. Heatmap showing prior interaction potential between the ligands and corresponding receptors. 
A

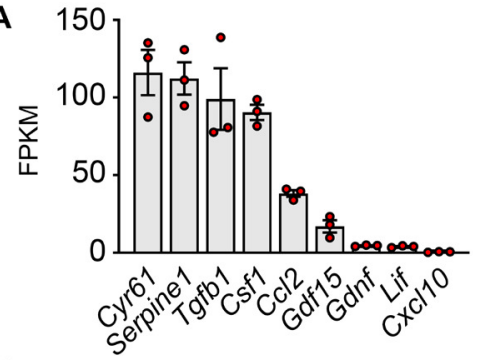

D
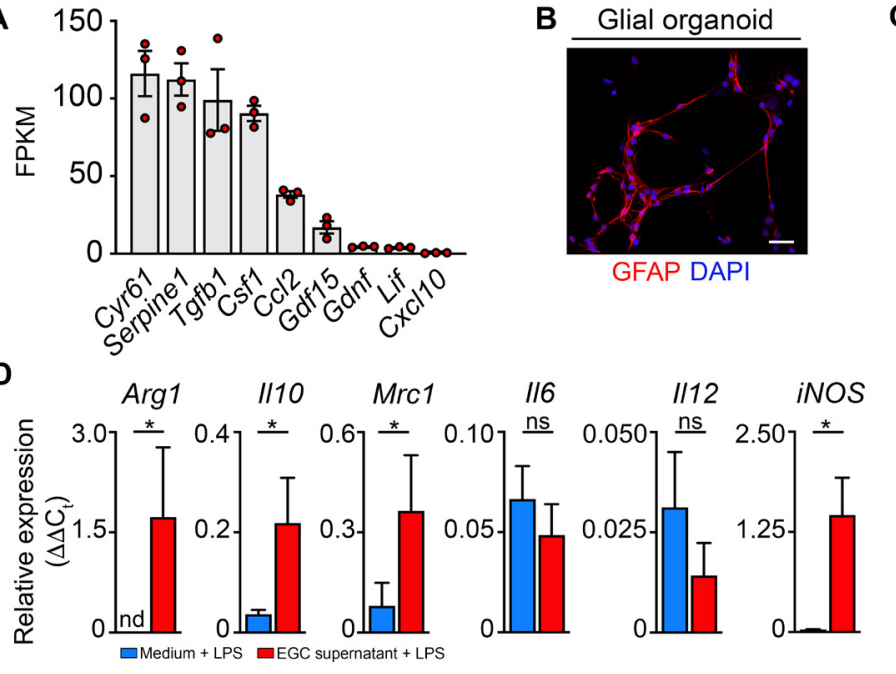

GFAP DAPI

E

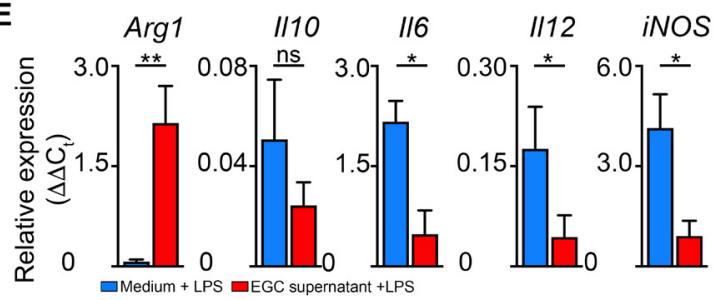

$\mathbf{F}$
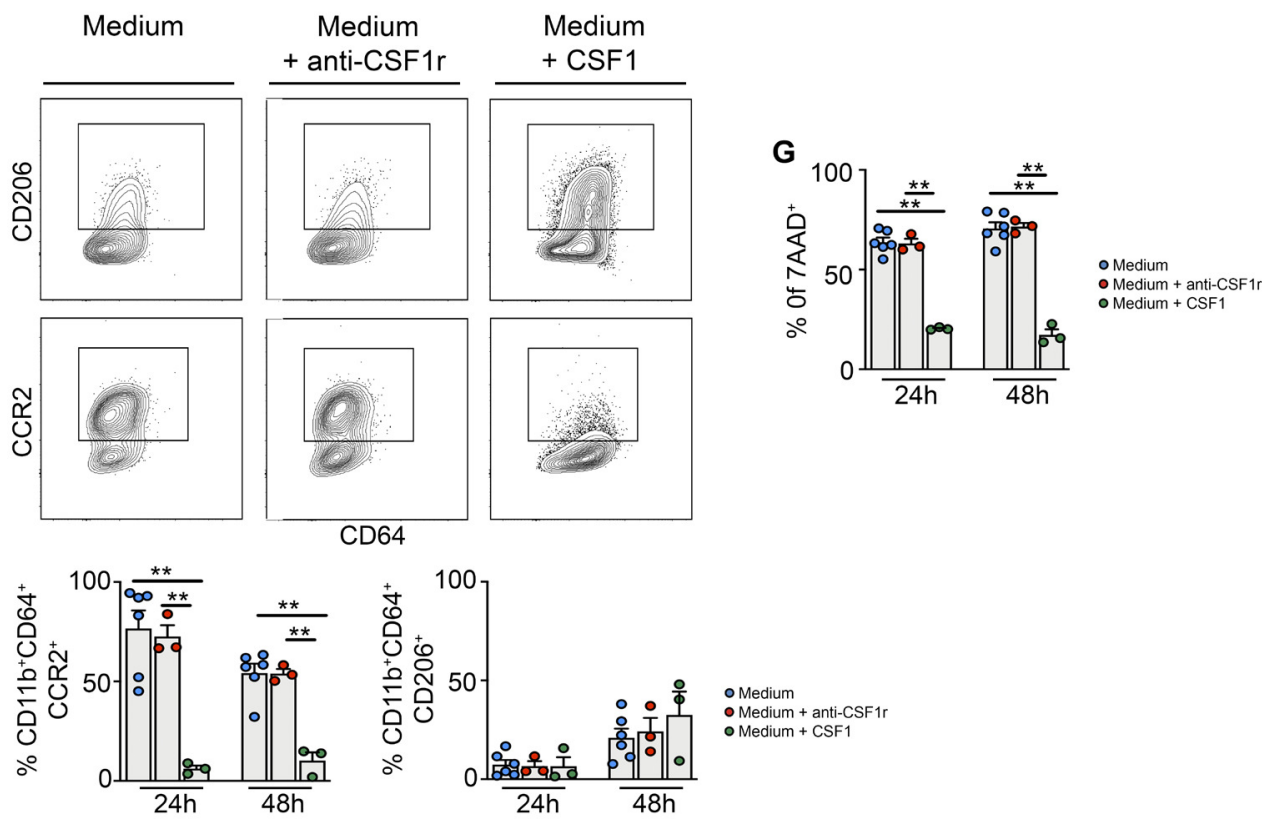

Supplementary Figure 6: Supernatant of neurosphere-derived EGCs blunts inflammatory response in monocytes upon stimulation with LPS. A. FPKM values of RNAseq performed on unstimulated neurosphere-derived EGCs. B. Neurosphere-derived EGCs stained with GFAP (red) and DAPI (blue). Scale bar $40 \mu \mathrm{m}$. C. BM monocytes were cultured for $18 \mathrm{~h}$ with/without EGC supernatant followed by LPS stimulation (100 $\mathrm{ng} / \mathrm{mL}$ ) for $6 \mathrm{~h}$. Relative mRNA levels for pro- and anti-inflammatory cytokines normalized to the housekeeping gene rp/32 are shown. D. Relative mRNA levels for pro- and anti-inflammatory cytokines normalized to the housekeeping gene $r p / 32$ in Ly6 $\mathrm{C}^{\mathrm{hi}}$ monocytes from the muscularis 24 post-injury and cultured $18 \mathrm{~h}$ with or without EGC supernatant and with LPS $(100 \mathrm{ng} / \mathrm{mL})$ for $6 \mathrm{~h}$. E-G. BM monocytes were cultured for 24-48h with medium alone, supplemented with anti-CSF1r $(5 \mu \mathrm{g} / \mathrm{mL}$ ) or CSF-1 (50 ng/mL). E. Contour plots of the expression of CD206 (top) and CCR2 (bottom) at $48 \mathrm{~h}$ of culture. F. Quantification of $7-\mathrm{AAD}^{+}$cells in BM monocytes cultured for $24 \mathrm{~h}$ and $48 \mathrm{~h}$. G. Percentage of CCR2 ${ }^{+}$and CD206 ${ }^{+}$cells in the live CD45 ${ }^{+}$CD11 $\mathrm{b}^{+}$Ly6G- CD64 $4^{+}$population. C-D. t-test. F-G; one-way ANOVA. * $p<0.05 ;{ }^{* *} p<0.01$. 
bioRxiv preprint doi: https://doi org/10.1101/2021.06.10.447700; this version posted June 10, 2021. The copyright holder for this preprint

\section{References}

1. Lennon VA, Sas DF, Busk MF, et al. Enteric neuronal autoantibodies in pseudoobstruction with small-cell lung carcinoma. Gastroenterology 1991;100:137-42.

2. De Schepper S, Verheijden S, Aguilera-Lizarraga J, et al. Self-Maintaining Gut Macrophages Are Essential for Intestinal Homeostasis. Cell 2018;175:400-415 e13.

3. Soret R, Coquenlorge $\mathrm{S}$, Cossais $\mathrm{F}$, et al. Characterization of human, mouse, and rat cultures of enteric glial cells and their effect on intestinal epithelial cells. Neurogastroenterol Motil 2013;25:e755-64.

4. Mich JK, Signer RA, Nakada D, et al. Prospective identification of functionally distinct stem cells and neurosphere-initiating cells in adult mouse forebrain. Elife 2014;3:e02669.

5. Livak KJ, Schmittgen TD. Analysis of relative gene expression data using real-time quantitative PCR and the 2(-Delta Delta C(T)) Method. Methods 2001;25:402-8.

6. Haimon Z, Volaski A, Orthgiess $\mathrm{J}$, et al. Re-evaluating microglia expression profiles using RiboTag and cell isolation strategies. Nat Immunol 2018;19:636-644.

7. Kim JS, Kolesnikov M, Peled-Hajaj S, et al. A Binary Cre Transgenic Approach Dissects Microglia and CNS Border-Associated Macrophages. Immunity 2021;54:176-190 e7.

8. Jaitin DA, Kenigsberg E, Keren-Shaul H, et al. Massively parallel single-cell RNA-seq for marker-free decomposition of tissues into cell types. Science 2014;343:776-9.

9. Kohen R, Barlev J, Hornung G, et al. UTAP: User-friendly Transcriptome Analysis Pipeline. BMC Bioinformatics 2019;20:154.

10. Love MI, Huber W, Anders S. Moderated estimation of fold change and dispersion for RNA-seq data with DESeq2. Genome Biol 2014;15:550.

11. Aibar S, Gonzalez-Blas CB, Moerman T, et al. SCENIC: single-cell regulatory network inference and clustering. Nat Methods 2017;14:1083-1086.

12. Yu G, Wang LG, Han Y, et al. clusterProfiler: an R package for comparing biological themes among gene clusters. OMICS 2012;16:284-7.

13. Aran D, Looney AP, Liu L, et al. Reference-based analysis of lung single-cell sequencing reveals a transitional profibrotic macrophage. Nat Immunol 2019;20:163172.

14. Heng TS, Painter MW, Immunological Genome Project C. The Immunological Genome Project: networks of gene expression in immune cells. Nat Immunol 2008;9:1091-4. 